This is a Library Circulating Copy

which may be borrowed for two weeks.

For a personal retention copy, call

Tech. Info. Dívision, Ext. 6782

\title{
LBL-7813 UC-95d
}
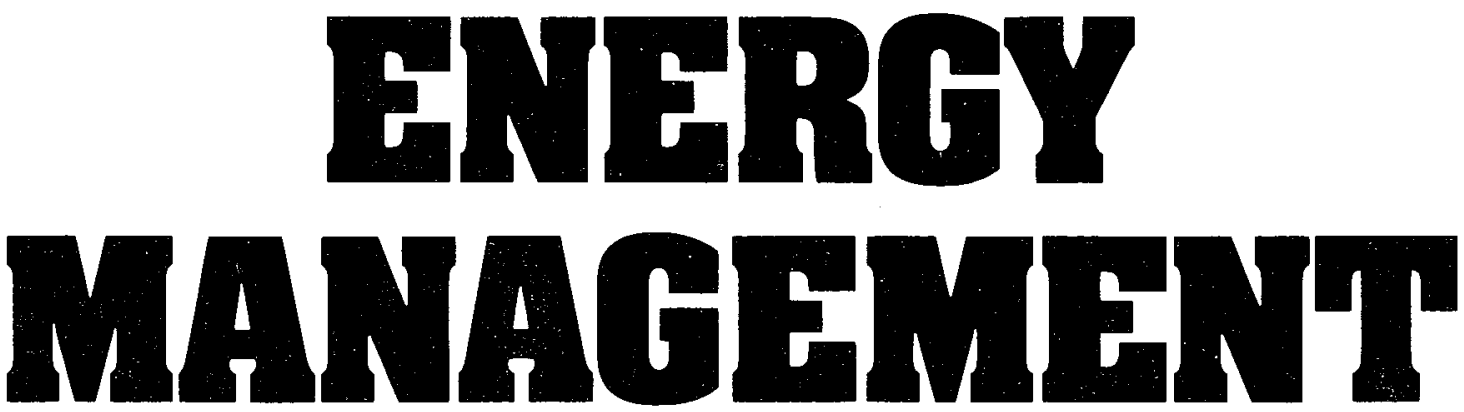

\section{A Program of Energy Conservation for the}

Community College Facility

RECEIVED LAWRENCE: BBERKELEY LABCRATORY

DEC 41978

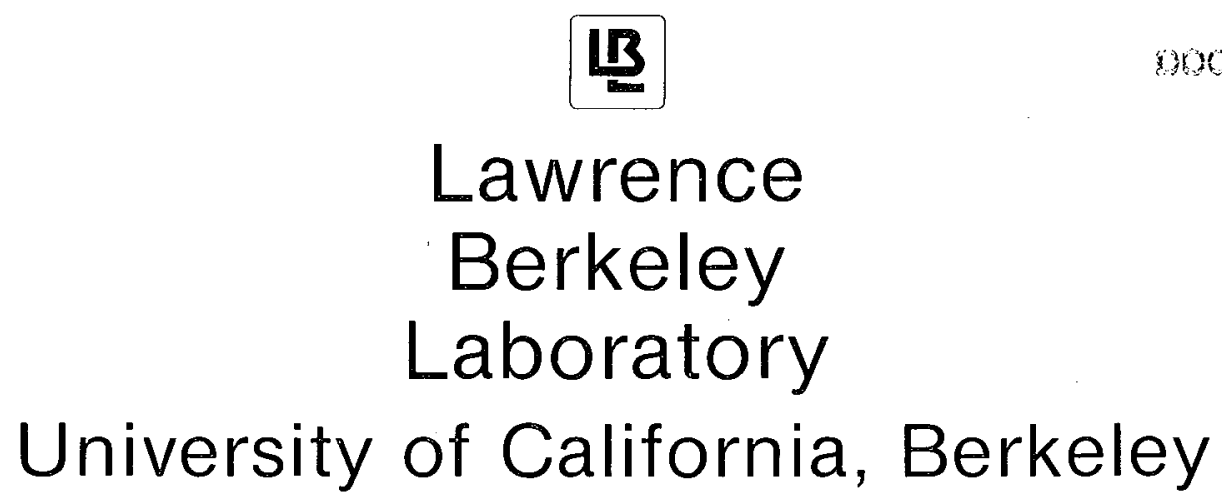

LIERARY AND OCUNENTS SECTION

Lawrence

Berkeley

Laboratory

Prepared for the U.S. Department of Energy under contract No. W-7405-ENG-48 


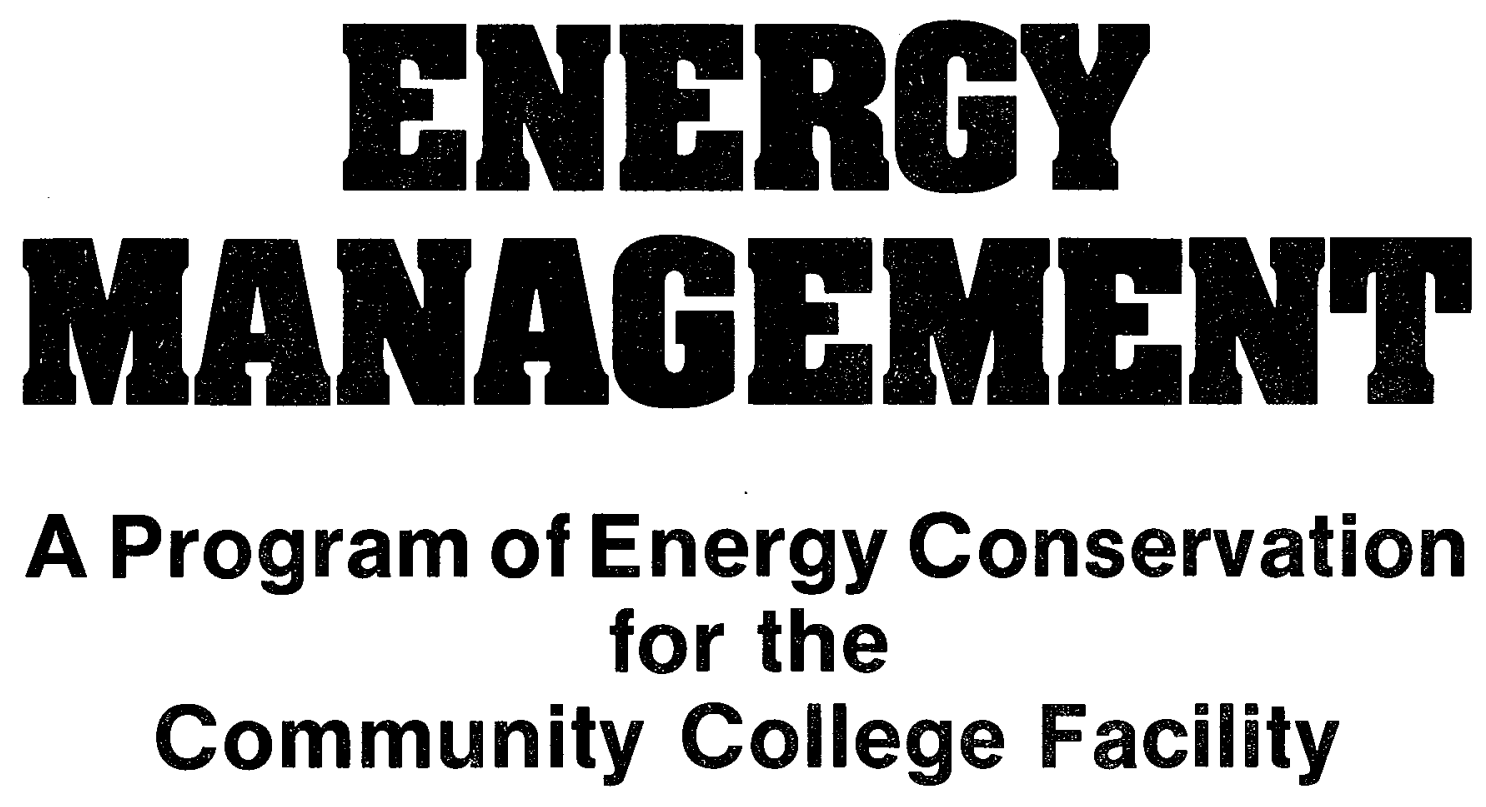




\section{LEGAL NOTICE}

This report was prepared as an account of work sponsored by the United States Government. Neither the United States nor the Department of Energy, nor any of their employees, nor any of their contractors, subcontractors, or their employees, makes any warranty, express or implied, or assumes any legal liability or responsibility for the accuracy, completeness or usefulness of any information, apparatus, product or process disclosed, or represents that its use would not infringe privately owned rights.

Printed in the United States of America Available from

National Technical Information Service

U. S. Department of Commerce

5285 Port Royal Road

Springfield, VA 22161

Price Code: 100-125 


\section{Contents}

Acknowledgments

The TEEM Approach to Energy Conservation

\section{PROGRAM IMPLEMENTATION}

1 Establish a Task Force

2 Establish an Action Plan

3 Energy Monitoring

4 Setting Goals

5 Energy Audit

6 Communication

7 Building and Equipment Survey

8 Follow-up

9 Implementaion of Measures

10 Monitor Improvements

11 Institutional Barriers

12 Sharing the Knowledge

13 Program Continuation

\section{APPENDIXES}
A Sample Board Policy Statement
B Metering and Monitoring
C Performing an Energy Audit
D Energy Conservation Checklist and Building Survey Forms
E Lighting
F Heating, Ventilating, and Air Conditioning (HVAC)
G Building Operation
H Food Preparation and Storage
I Service Hot Water
$J$ Economics
K Conversion Factors
L General Glossary
M Interested Associations
N Bibliography 


\section{Acknowledgments}

The TEEM concept, or Total Educational Energy Management approach, was developed by Calvin Anderson of the Colorado Department of Education and James McClure of the Pacific Gas and Electric Company. They provided workbooks similar to this one for use in $\mathrm{K}-12$ schools and applied the programs with excellent results. This workbook drew heavily on the ideas and material they had developed, but has been oriented toward the administrators, faculty, and students of a college campus. It was compiled by Harry Miller and Peter Rowe of the Lawrence Berkeley Laboratory and prepared for the press by the Laboratory's Technical Information Department. We gratefully acknowledge the earlier work of the Interstate Energy Conservation Leadership Project, the Educational Facilities Laboratories, the Pacific Gas and Electric Company, the Association of Physical Plant Administrators, and the Federal Energy Administration. 


\section{The TEEM Approach to Energy Conservation}

This handbook was developed to help you in assessing and improving the energy efficiency of your community college facility.

In the TEEM approach (Total Educational Energy Management) to energy conservation, each campus building and activity is considered as a unique system which uses energy to fulfill the specific needs of educational programs. The TEEM program, flexible by design, provides a framework within which the college community can systematically consider and implement a great number of effective energy-saving practices.

Initially, TEEM is a labor-intensive approach which requires the commitment and participation of all segments of the college community. The investment of time and effort needed to establish the program will, however, be returned with dividends as energy savings are realized.

The TEEM program presented here is much more than a compilation of suggestions about turning off unused lights and lowering thermostat settings. As an effective energy management (and money saving) program, TEEM defines a series of tasks selected, ordered, and implemented in such a way as to achieve two basic objectives: (1) reducing campus energy requirements, and (2) meeting those reduced energy requirements more efficiently without adversely affecting the quality of educational programs.

This guide to large-scale energy conservation on college campuses includes step-by-step procedures for establishing a program task force, defining specific tasks, and assigning responsibilities. Action plans are developed, energy consumption monitored, goals set, and conservation measures implemented. A series of appendices provides more detailed information, charts, and worksheets related to all aspects of energy use.

The TEEM program provides the basic structure for achieving a significant reduction in campus energy costs. 


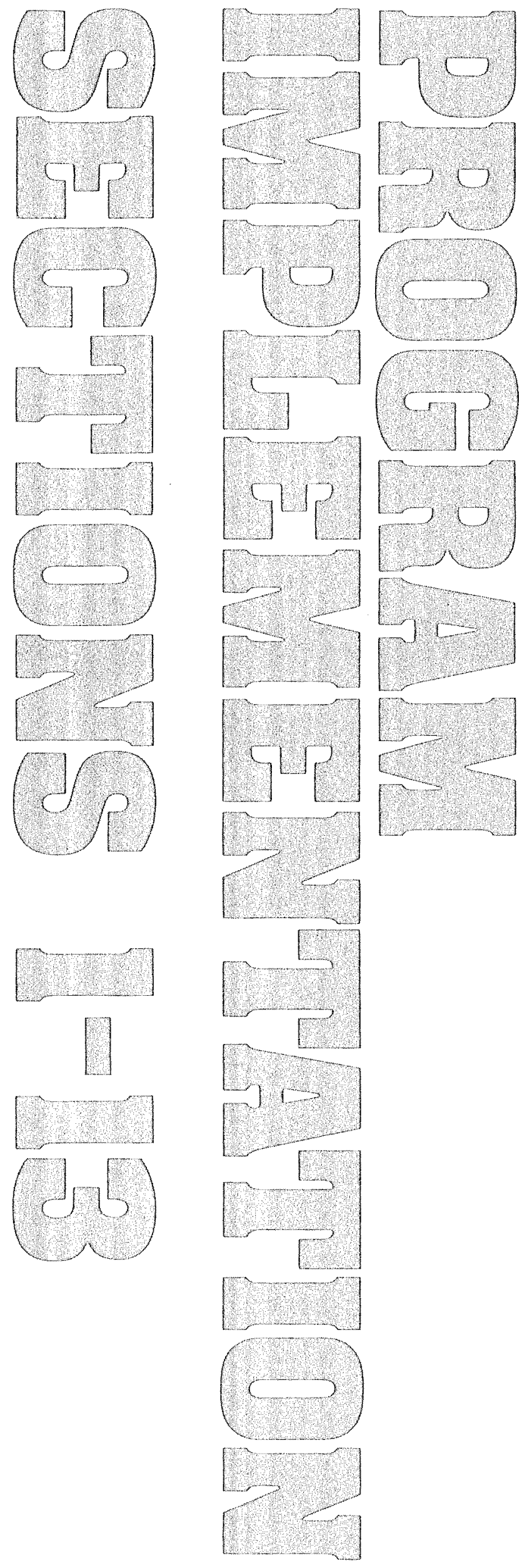




\section{Establish a Task Force}

Responsibility for the energy management program should be shared by many of the people who will be directly affected by its results. In addition, the success of the program depends on the coordinated effort of the entire college community, from the student to the Governing Board.

\section{Governing Board Policy Mandates}

The support of the Governing Board must be enlisted early in the program. The Board must, as a matter of policy, declare energy conservation on campus to be a high priority action item. Because the program can only be as strong as the commitment, approval, and financial support received from upper management this is an essential part of the program. The Board must assign to a Campus energy Task Force, the authority and responsibility to take actions to save energy. Appendix $A$ is a sample policy statement issued by one college district in northern California.

\section{Task Force Members}

The Task Force must include persons who are in positions of responsibility and accountability. It is therefore essential that an Energy Task Force, composed of most of the people listed below, be established to implement the program.

College President. The president must provide the leadership and direction to make the program work. The president has a unique position of authority over, and responsibility for, the overall operation of the college, and has the most immediate contact with its Governing Board. It will be the president who will present the program to the Board and obtain its support, and who will, possibly via a designated representative, follow through to ensure that the Task Force achieves its purposes. This representative, referred to as the "Campus Energy Coordinator," will conduct the regular Task Force meetings and distribute information.

Dean of Curriculum Planning. The dean will be involved in consideration of changes in classroom loading and building usage related to energy conservation. In addition, the integration of energy conservation into the existing curricula and the community awareness seminars will be areas in which the dean will provide leadership.

Faculty Members. People from the departments of physics, economics, and social sciences will likely be interested in participating in the program. Faculty members may serve as technical advisors to the Task Force in addition to giving input about their building needs. On some campuses, faculty involvement will be coordinated through the academic senate. 
Student Representative(s). Aside from presenting a student perspective on matters such as building access and classroom comfort, the students can be responsible for some communication processes and for monitoring energy use.

Business Manager. The business manager will most likely be the person responsible for the budgetary considerations for the energy program's needs. In addition, he will be able to relate energy savings to availability of funds for educational programs.

Maintenance and Operations Engineer. As the person responsible for both the envelope and mechanical systems of all the college buildings, the plant engineer will be an important member of any team dealing with alterations to those buildings. Many plant engineers have already implemented energy conservation measures and should be encouraged to share their experience with the rest of the Task force.

Food Service Supervisor. Because food preparation and dishwashing use a significant amount of energy, and because procedural or equipment changes in the kitchen will be considered, the food service supervisor should be involved in the program.

Transportation Coordinator (where applicable). The transportation coordinator will be asked to reduce energy use in campus transportation through such practices as carpooling.

Utility Company Representative. The utility company will be an important resource for technical information, rate schedule data, and information about past conservation programs.

\section{Specific Task Assignments}

Responsibilities have to be defined precisely within the Task Force. Each member should have a list of specific tasks which he, or she, will perform. This "specific task" approach serves to counteract the feeling of being overwhelmed by the amount of work to be done. It should be remembered that the program is 
designed to be initially labor-intensive and that a commitment of staff time will be required to meet the goal of saving energy.

\section{Minutes of the Meetings}

It is extremely important that accurate written records of each meeting of the Energy Conservation Task Force be kept and made available for reference. Ideas and recommendations will probably be numerous and varied. Written records will be essential to making the most effective use of your time. In addition, recording recommendations will help to identify any institutional problems when evaluating the amount of time which was needed for implementation. 


\section{Establish an Action Plan}

The first thing the Task Force should do is define its tasks very precisely and decide who should perform each one. It is usually helpful to set up a time line, or critical path diagram, once the activities are scheduled. The deadlines should be set by the person who will have to meet them. Planning should be done for a period as far in advance as is practical. Each member of the team should have a copy of the list of activities and the persons responsible for each.

The calendar of activities might consist of some or all of the following elements, as well as any others deemed appropriate:

Month 1: Establish the Task Force and assign tasks

Set goals for energy savings

Start energy monitoring (meter reading)

Do a building, equipment, and plant usage survey

Perform an energy audit of past usage

Month 2: Examine classroom loading and night activities to find more efficient modes of operation

Validate energy monitoring by comparison with utility bills

Distribute, compile, and review "Energy Grams" (see Section 6)

Review results of energy audit, surveys, energy grams, etc., and make recommendations

Month 3: Prioritize recommendations

Develop plans for public information program

Report to Board and request any necessary funds

Implement maintenance and operations measures

Evaluate effectiveness of program and of specific measures via energy monitoring

Exchange visits with teams from other campuses or hold seminars for colleges that are interested in starting similar programs 


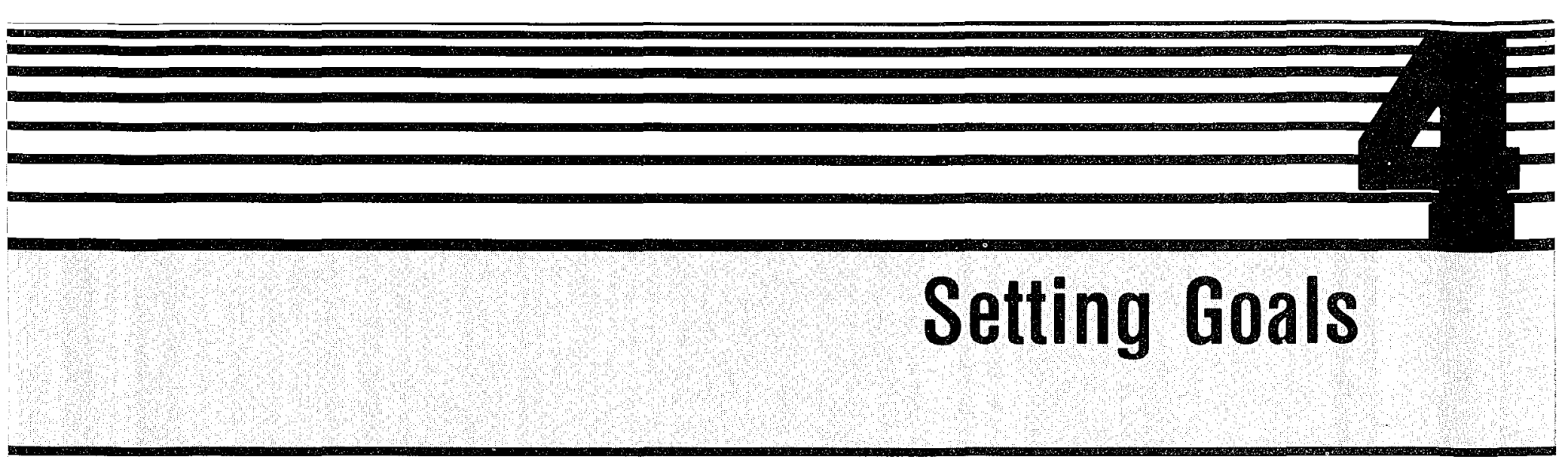

The Task Force should establish some realistic conservation goals, based on the records of past usage, the building and equipment survey, and the experience of any previous conservation programs.

It is reasonable to expect a $10 \%$ reduction in energy consumption almost immediately, a $15 \%$ reduction after about six months, and a $25 \%$ reduction by the end of the first year. These are, of course, only approximations; actual savings will vary greatly, depending on the degree of commitment and participation and on energy conservation measures instituted before the formal Task Force approach was undertaken. 


\section{Communication}

\section{Committee}

The need for communication among the various Task Force members will be identified at the first meeting. It is expected that regular meetings and memorandums can meet most of these communication needs. It will also be useful to establish standard reporting schedules and procedures for Task Force members.

\section{Campus}

The college community should be recognized as a human energy resource and used as such. Mechanisms such as flyers, posters, and items in the school newspaper, should be chosen early in the program to make the students, faculty, and staff aware that an energy conservation program is evolving, and to solicit help, suggestions, recommendations, and notifications of flagrant energy waste or mismanagement. One successful communication device is the "Energy Gram." Distributed, with instructions for use, throughout the campus, and collected and compiled at one central location, such as the student center or the bookstore, Energy Grams serve as an effective energy-conservation suggestion program.

\section{Community}

As the program evolves, thought should be given to integrating energy conservation into the curricula, and to holding community awareness seminars about energy and its management. 


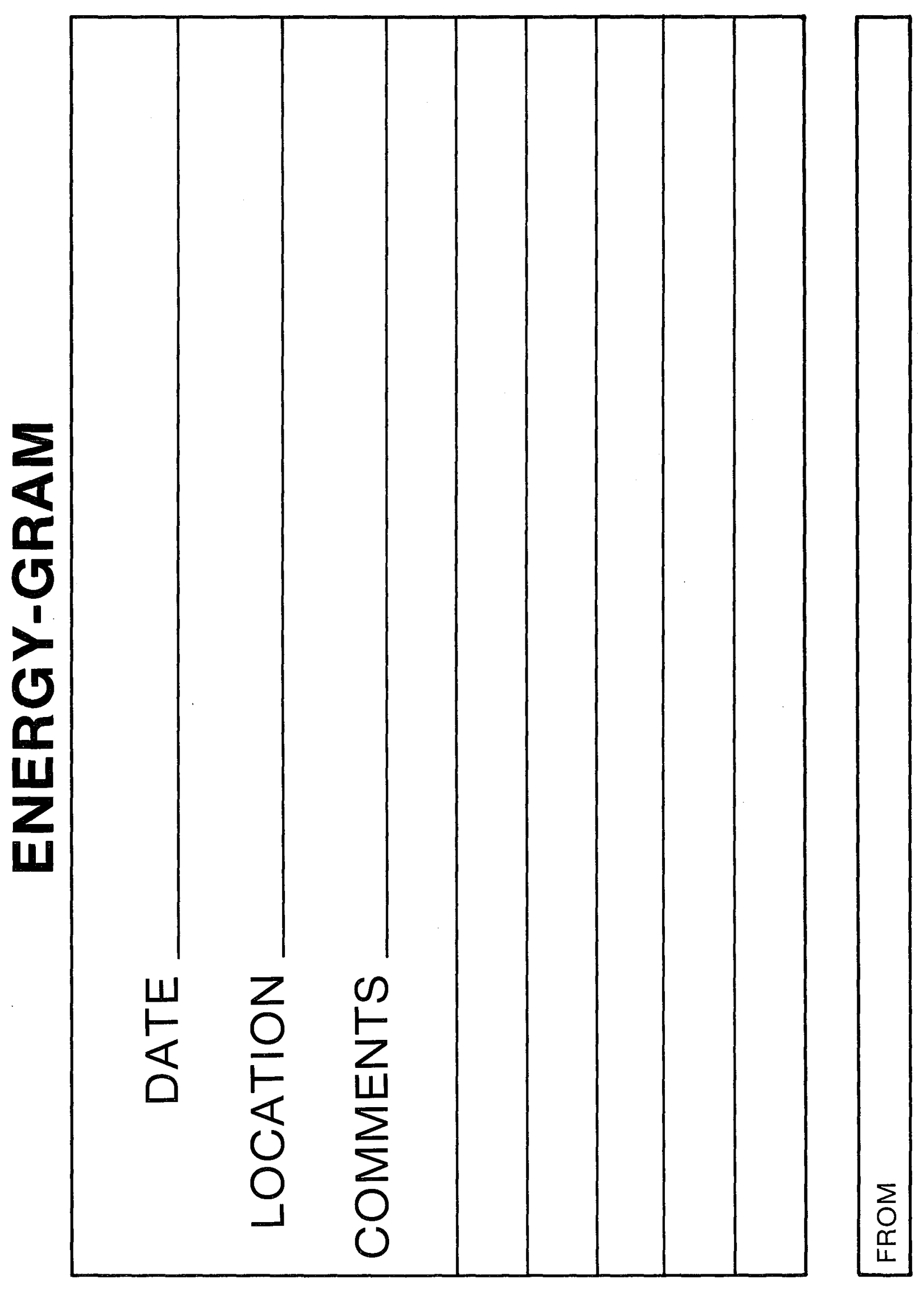




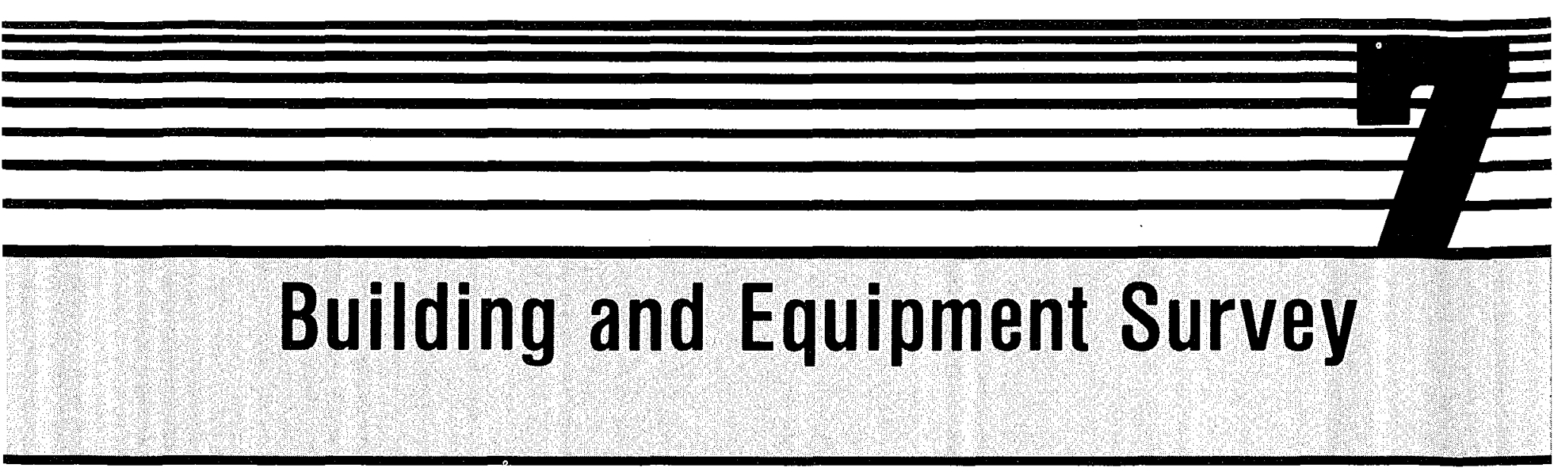

A building "walkthrough" should be conducted to identify areas of possible energy savings. The survey should be conducted by the entire Energy Task Force. A utility representative or other energy expert might also be invited along to participate. The tour should be led by the maintenance and operations engineer. A few basic tools will be needed: a flashlight, pencil and paper, a measuring tape, a light meter, a thermometer, and maps or floor plans of the college buildings.

Appendix D contains an "Energy Conservation Checklist" to alert you to some typical areas where energy can be saved. Worksheets are included to help generate ideas about ways energy can be saved in cam pus buildings and to provide a record of survey findings. A "Plant Usage Schedule" form is provided to help you assess your classroom loading and hours of operation. This is an important part of the survey as significant energy savings can be realized by consolidating activities and shutting down some buildings or systems. 


\section{Implementation of Measures}

Energy conservation measures generally fall into one of the following categories:

Alterations in maintenance and operations procedures include lowering thermostat settings, consolidating activities to use fewer buildings, adjusting work schedules to take maximum advantage of daylight, and accelerating cleaning and tuneup schedules for mechanical systems. These changes are usually implemented by in-house personnel, have short pay-back periods, and can save significant amounts of energy.

Adjustments to existing environmental systems typically include such actions as modifying lighting systems (adding time clocks, changing lamp types at replacement time), reducing heating and cooling losses by upgrading insulation and weatherstripping, and fine tuning of HVAC systems (proper maintenance, rezoning, timers). Some of these actions may involve capital expenditures; their priority must be based on a life-cycle costing method which considers operating costs.

Converting to new systems is an option that the Task Force will consider later in the program. This handbook is concentrating on measures that can be implemented in the short term. 


\section{Monitor Improvements}

The benefit to be derived from each proposed conservation action can only be estimated. There are many factors which will determine the actual energy savings. Improper installation of equipment or failure to comply with recommended operational procedures will yield disappointing results. To be able to identify such problems early, it is important to maintain the daily energy monitoring routine mentioned previously. In addition, monitoring will enable you to experimentally evaluate the relative success of various actions and to plan the implementation of other recommendations accordingly. 


\section{Institutional Barriers}

It may be worthwhile to have a Task force meeting for the primary purpose of analyzing and predicting institutional barriers to implementation of some changes and, therefore, their effect on the success of the program.

These problems can range from budget submittal deadlines that do not coincide with the needs of the program, to faculty or student reluctance to participate, to a decrease in participation as the novelty of the program wears off.

These institutional problems, rather than any technical or financial hindrances, are often reasons for the eventual failure of energy conservation programs. Therefore, the importance of dealing with such institutional barriers before they become problems cannot be overemphasized. 


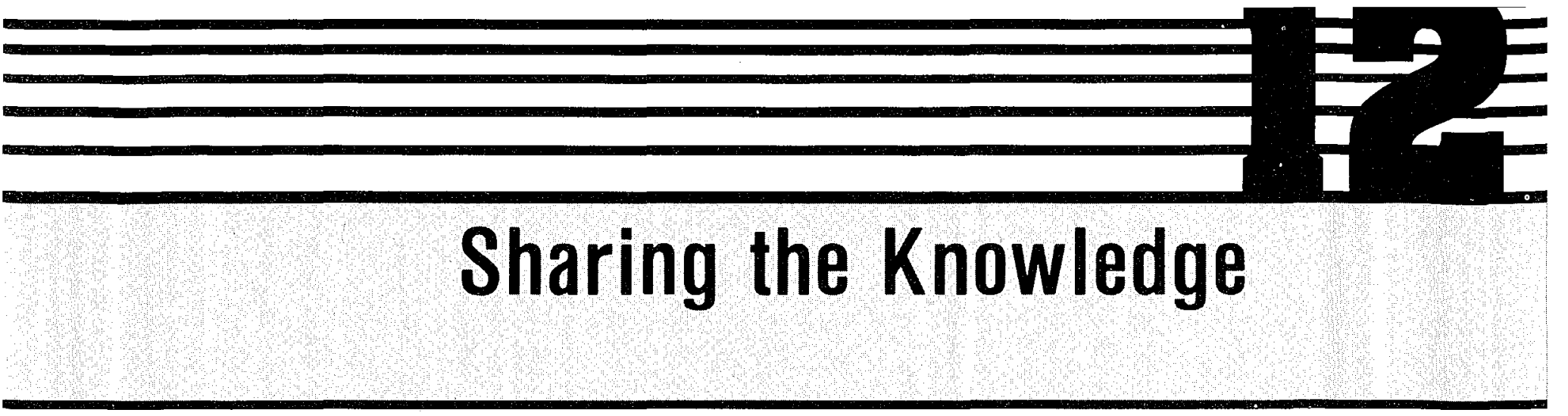

The essence of education is communication. Those who have some knowledge meet with those who seek it. As the energy conservation program begins to produce results, the Task Force should consider sharing the benefits of its experience. One method of doing this is to hold a seminar with the Task Forces of other community colleges that are engaged in similar programs, and with those who are about to begin such programs.

Organizational experience as well as technical results should be exchanged. It is important to know which methods have succeeded, and which have failed, as well as what institutional problems have come up and how they have been solved. 

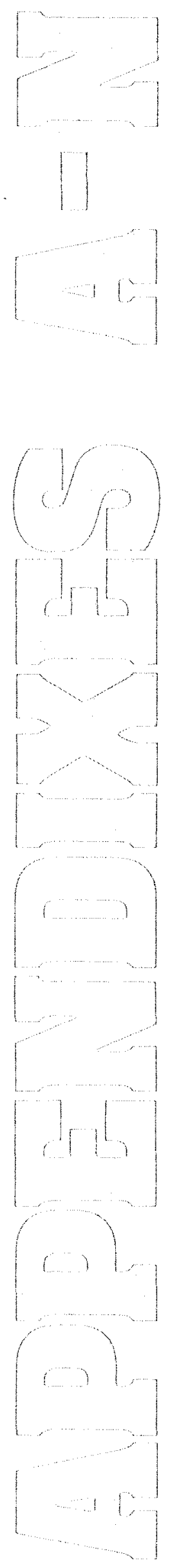


\section{ENERGY AND RESOURCES CONSERVATION}

The Board recognizes the responsibility of the College to: reduce resource wastes to as low a level as is practicable without compromising the basic mission of the college; to help students and members of the community understand the need for wise use of natural resources; to promote an understanding of the relationship between reduced consumption and the quality of our environment; and to demonstrate leadership in voluntary efforts to reduce use of certain critical resources. Furthermore, the Board recognizes the need to provide the necessary funding to assure maximum effectiveness of the program.

A program of effective energy and other resources management must be vigorously pursued in order to maintain a stable academic environment. Recognizing this need for a cooperative campus and community effort, the Board directs the Superintendent/President to formulate and maintain a program of effective energy and resources conservation.

\section{Approved}

Administrative Council $1 / 26 / 78$

Faculty Senate $2 / 28 / 78$

ASB 3/8/78 


\section{ADMINISTRATIVE REGULATION IMPLEMENTING BOARD POLICY ENERGY AND RESOURCE CONSERVATION}

The following procedures will be developed to implement the Energy and Resources Conservation policy:

1. Solicit the active participation and support of students, staff, faculty and community members in development and operation of the program.

2. Assure that new construction accomplishes conservation through efficient use of energy and of resources, which may include the use of life cycle costing techniques.*

3. Provide for modifications of the physical plant and grounds as necessary for energy and water conservation, where a clear benefit of such modification can be demonstrated.

4. Establish an ongoing campus and community education program to increase conservation awareness.

5. Provide for a plan to monitor energy use at the College and to carry out regular maintenance procedures necessary to reduce energy waste.

6. Include consideration of possible energy savings procedures for the College transportation system.

7. Include consideration of alternative energy sources, where such sources promise improved stability of supply, economic benefit, or other clear advantage.

8. Include establishment of a waste management program.

*Life-cycle costing: The calculation of the cost of a product on the costs for its expected "lifetime," that is, the initial cost of acquisition or development, the anticipated cost of maintenance and repairs, the cost of energy to run it during its lifetime, and-in some cases-the cost of disposal. 
The following pages provide instructions for reading gas and electrical meters. They should be read carefully to ensure full understanding of the idiosyncracies of utility meters.

Meters should be read at approximately the same time each day. The chart provided herein is designed for meter readings taken at the end of the day. If you read the meter in the morning, you are measuring the previous day's consumption. Both the number read directly from the meter and the amount of energy or fuel consumed since the last reading must be recorded. The weekly subtotals will be added to become the monthly totals to be entered on the "Energy Audit" chart. Remember that 1 cubic foot of gas $=1000 \mathrm{Btu}$; so 100 cubic feet $=1$ therm and 1 kilowatt-hour of electricity $=3413$ Btu. 


\section{HOW TO READ A GAS METER}

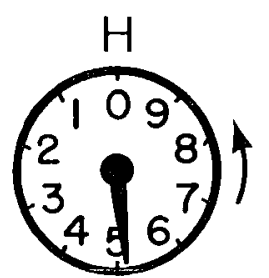

(Hundred thousand)

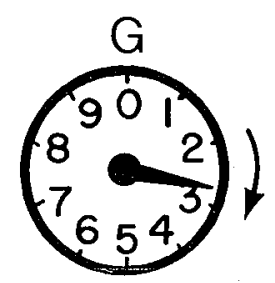

(Ten thousand)

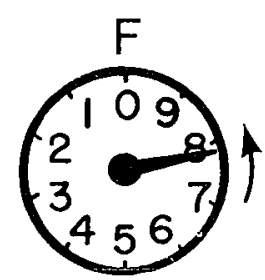

(Thousand)

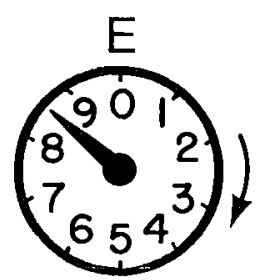

(Hundred)

\section{CUBIC FEET}

Your gas meter measures the flow of natural gas in cubic feet. A cubic foot is the volume of a container that is 1 foot on all sides. The first dial, dial "E", actually indicates in hundreds of cubic feet. The pointer on dial " $E$ " is between 8 and 9 . This tells you that more than 800 but less than 900 cubic feet of gas have been used. It is read as 8 . You must add two zeros to the number on dial " $E$ " in order to read it correctly -800 .

Each number on dial " $F$ " indicates the number of thousand cubic feet. In this case, the pointer on dial " $F$ " is touching 8 , but the pointer on dial "E" shows us that the pointer has a few numbers yet to go before it has made a complete circle. Therefore, dial "F" is read as 7 , showing that 7,000 cubic feet of gas has been used.

Dial "G" indicates the number of cubic feet of gas in units of 10,000. Dial "G", therefore, tells you that 20,000 cubic feet of gas have been used.

The unit of gas used on dial " $H$ " is 100,000 cubic feet. Dial " $H$ " is read as 5. The pointer on dial " $G$ " tells you that the pointer on dial " $\mathrm{H}$ " actually has passed 5 . The 5 tells you that the amount of gas indicated is more than 500,000 cubic feet.

The complete reading on this gas meter is 5278 ; by adding the zeros, the actual reading is 527,800 cubic feet.

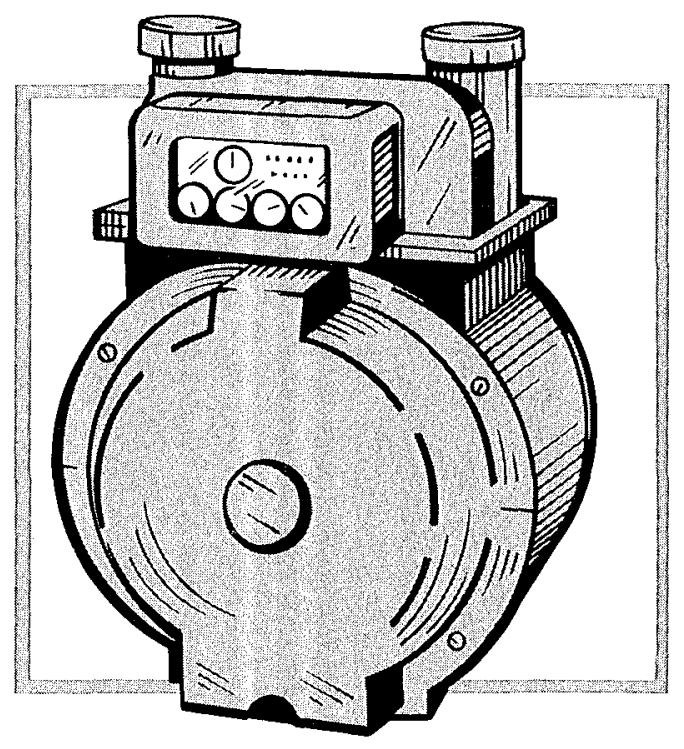

\section{HOW MUCH NATURAL GAS HAS BEEN USED?}

As an example, let's say that the reading on your gas meter for the following month is 5591. By subtracting the old number (5278) from the new number (5591), you find that the difference is 313 . To get the real reading, you must add two zeros to this number, because the last number is actually hundreds of cubic feet of gas. The meter tells you, therefore, that you have used 31,300 cubic feet of gas since the last reading. 


\section{HOW TO READ AN ELECTRIC METER}

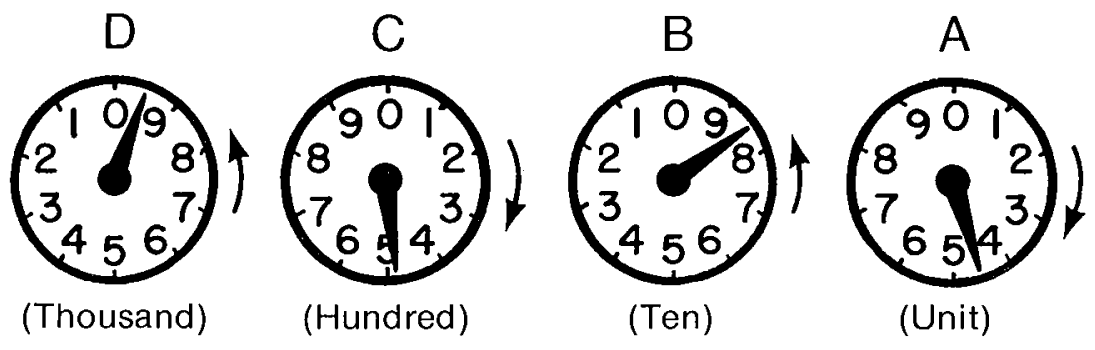

KILOWATT HOURS

To read your electric meter, first look at dial "A." The pointer is between the numbers 4 and 5 . This means that more than 4 but less than 5 kilowatt-hours of electricity has been used. We say that dial "A" read 4.

On dial " $\mathrm{B}$ " the pointer is between 8 and 9 . This means that more than 80 but less than 90 kilowatt-hours have been used. Dial " $B$ " reads as 8 .

Dial " $C$ " shows the pointer touching number 5. By looking back at dial "B", however, we see that the pointer on that dial has not quite made a complete circle yet. If it had, the pointer would be on zero or beyond. Therefore, we read dial " $\mathrm{C}$ " as 4 .

The pointer on dial "D" is between 9 and zero. This means that more than 9,000 but less than 10,000 kilowatt-hours have been used. Again, we say that dial " $D$ " is read as 9 .

The total reading is 9484 . Note that unlike the gas meter, no zeros have to be added to the reading on the electric meter.

\section{HOW MUCH ELECTRICITY HAS BEEN USED?}

Let's say that the following month the reading on the meter is 9515 . By subtracting the old number (9484) from the new number (9515), you find that the difference is 31 . In other words, the meter tells you that you have used 31 kilowatthours since the last reading. You can't tell how much electricity has been used with just one reading.

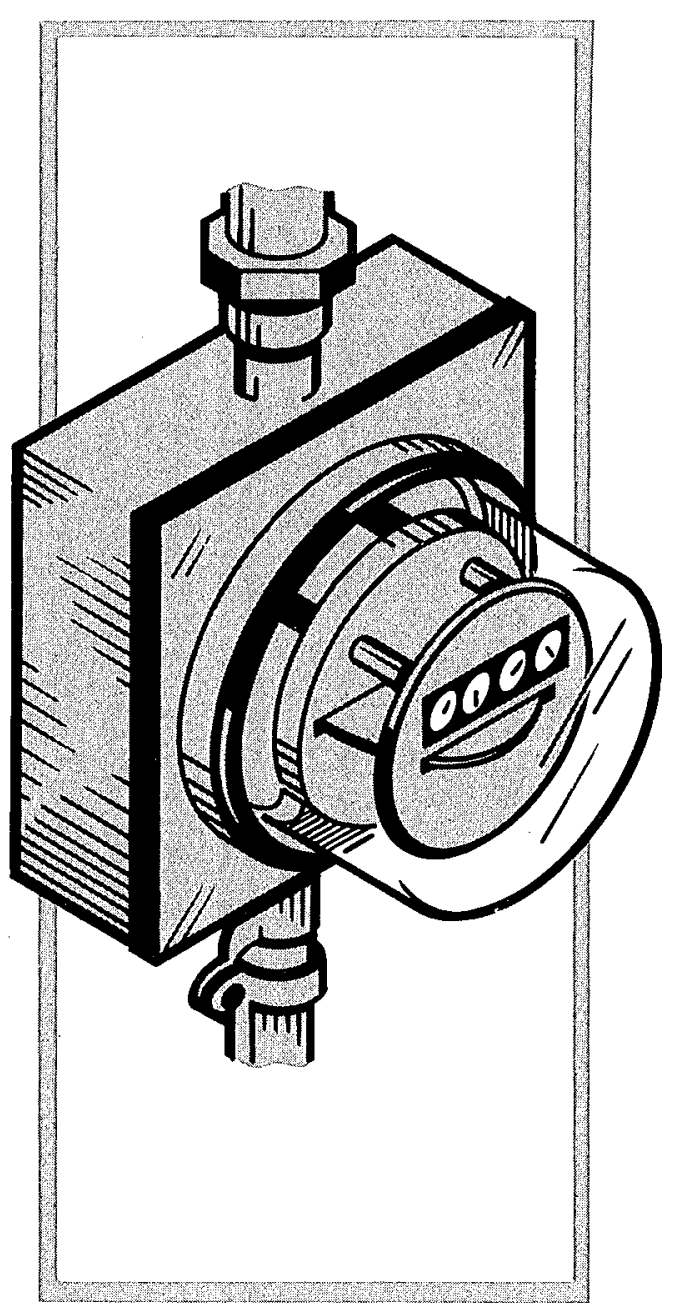


TEEM BUILDING ENERGY USAGE RECORD

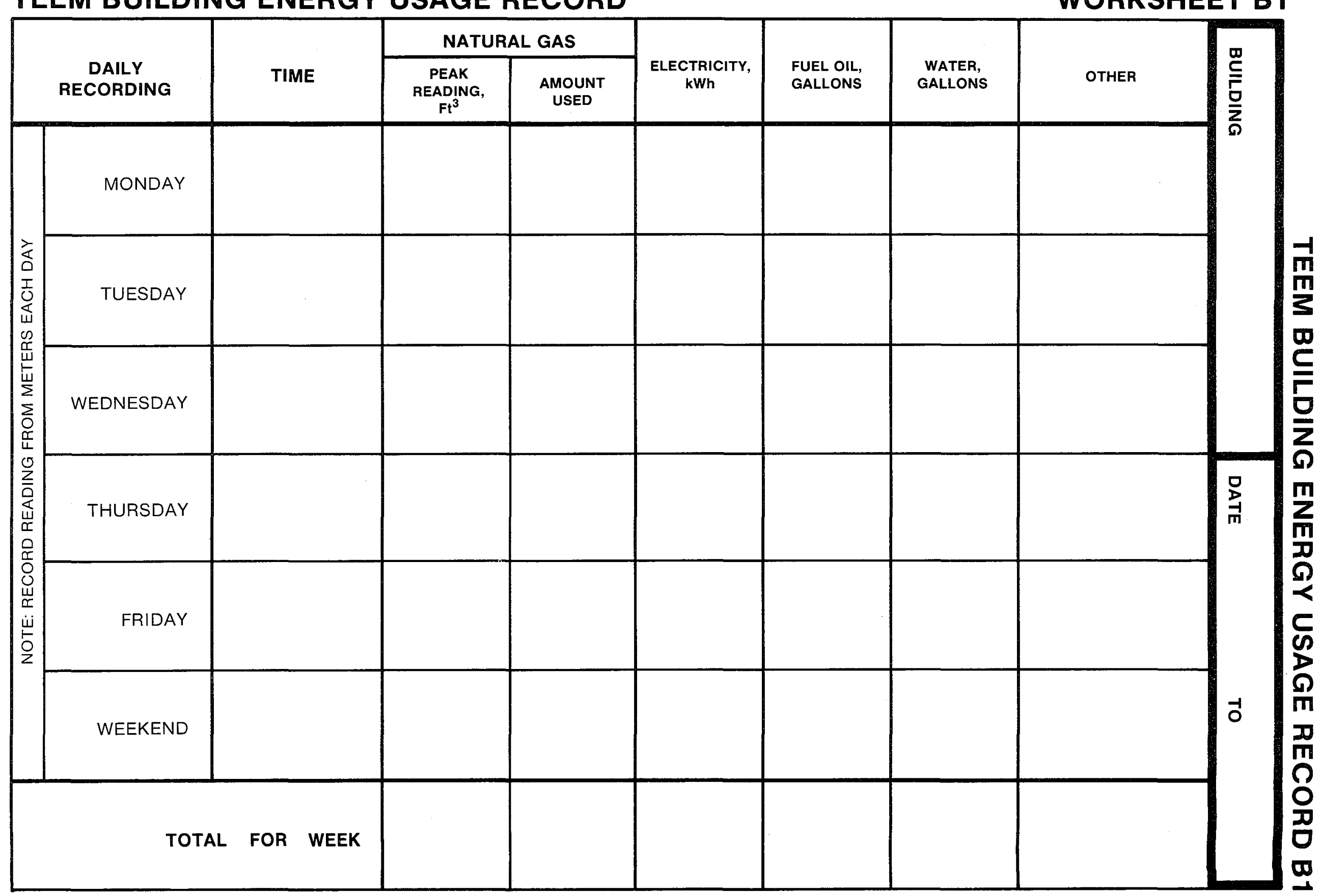




\section{Performing an Energy Audit}

STEP ONE. Assemble all energy bills from the past year. If some are missing, the billing department of your utility company can provide you with copies.

STEP TWO. Record the amount of energy used and the amount you were billed for the energy on Worksheet $\mathrm{C} 1$.

STEP THREE. Convert the amount of energy used to Btu's. The Btu (British thermal unit) is a common unit of measure for thermal energy. One Btu is the amount of energy required to heat 1 pound of water 1 degree Fahrenheit at standard physical conditions. Large quantitites of energy are often expressed in terms of millions of Btu's. Conversion of energy consumed to Btu's is accomplished by using the multipliers given on Worksheet $\mathrm{C} 1$. These multipliers are derived from the following equations which indicate the Btu content of various energy sources:

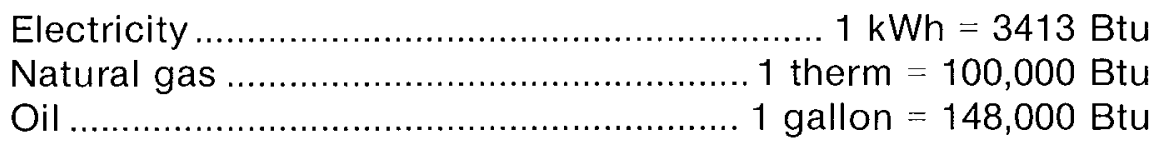

Note: Columns 3 and 4 of Worksheet $\mathrm{C} 1$ can be compressed to one step. Simply multiply column 2 by 0.003413 and enter the result in column 4 .

STEP FOUR. Add up the energy used from each source and enter the total energy used on Worksheet C2. Do the same for energy costs.

STEP FIVE. Calculate the energy used per square foot of floor space. Also, divide the energy used by the number of students served (full-time equivalent). It might be more useful to divide the energy used by the number of weekly student center hours (WSCH). Repeat these processes for energy costs, as indicated on Worksheet C2.

STEP SIX. Graph the data obtained from steps 4 and 5 . Besides providing a visual display of the information, this graph will serve as an aid for future comparisons.

STEP SEVEN. Using the graph derived in step six as a reference, plot the monthly energy usage and cost as you are billed for it. This comparison graph should be distributed and displayed to indicate the success of the program as it progresses. This display will also remind the college community to save energy. 


\section{WORKSHEET C1}

\begin{tabular}{|c|c|c|c|c|c|}
\hline \multirow{13}{*}{$\frac{\grave{z}}{\frac{\mathbf{v}}{\alpha}}$} & $\begin{array}{c}(1) \\
\text { MONTH }\end{array}$ & $\begin{array}{l}(2) \\
k W h\end{array}$ & $\begin{array}{c}(3) \\
\times 3413 \\
\text { Btu }\end{array}$ & $\begin{array}{c}(4) \\
\div 1,000,000 \\
\text { Btu }\end{array}$ & $\begin{array}{c}(5) \\
\operatorname{COST}\end{array}$ \\
\hline & JANUARY & & & & \\
\hline & FEBRUARY & & & & \\
\hline & MARCH & & & & \\
\hline & APRIL & & & & \\
\hline & MAY & & & & \\
\hline & JUNE & & & & \\
\hline & JULY & & & & \\
\hline & AUGUST & & & & \\
\hline & SEPTEMBER & & & & \\
\hline & OCTOBER & & & & \\
\hline & NOVEMBER & & & & \\
\hline & DECEMBER & & & & \\
\hline \multirow{13}{*}{$\frac{0}{4}$} & MONTH & THERMS & $\begin{array}{c}\times 100,000, \\
\text { Btu }\end{array}$ & $\begin{array}{c}\div 1,000,000 \\
\text { Btu }\end{array}$ & COST \\
\hline & JANUARY & & & & \\
\hline & FEBRUARY & & & & \\
\hline & MARCH & & & & \\
\hline & APRIL & & & & \\
\hline & MAY & & & & \\
\hline & JUNE & & & & \\
\hline & $J U L Y$ & & & & \\
\hline & AUGUST & & & & \\
\hline & SEPTEMBER & & & & \\
\hline & OCTOBER & & & & \\
\hline & NOVEMBER & & & & \\
\hline & DECEMBER & & & & \\
\hline \multirow{13}{*}{$\frac{1}{0}$} & MONTH & GALLONS & $\begin{array}{c}\times 148,000 \\
\text { Btu }\end{array}$ & $\begin{array}{c}\div 1,000,000 \\
\text { Btu }\end{array}$ & COST \\
\hline & JANUARY & & & & \\
\hline & FEBRUARY & & & & \\
\hline & MARCH & & & & \\
\hline & APRIL & & & & \\
\hline & MAY & & & & \\
\hline & JUNE & & & & \\
\hline & JULY & & & & \\
\hline & AUGUST & & & & \\
\hline & SEPTEMBER & & & & \\
\hline & OCTOBER & & & & \\
\hline & NOVEMBER & & & & \\
\hline & DECEMBER & & & & \\
\hline
\end{tabular}




\section{WORKSHEET C2}

\begin{tabular}{|c|c|c|c|c|c|c|}
\hline \multirow[b]{2}{*}{ MONTH } & \multicolumn{3}{|c|}{ COST } & \multicolumn{3}{|c|}{ USAGE } \\
\hline & $\begin{array}{l}\text { TOTAL } \\
\text { ENERGY }\end{array}$ & $\begin{array}{c}\text { PER } \\
\text { STUDENT }\end{array}$ & $\begin{array}{c}\text { PER } \\
\mathrm{Ft}^{2}\end{array}$ & $\begin{array}{l}\text { TOTAL } \\
\text { ENERGY }\end{array}$ & $\begin{array}{c}\text { PER } \\
\text { STUDENT }\end{array}$ & $\begin{array}{r}\text { PER } \\
\mathrm{Ft}^{2}\end{array}$ \\
\hline JAN. & & & & & & \\
\hline FEB. & & & & & & \\
\hline MAR. & & & & & & \\
\hline APR. & & & & & & \\
\hline MAY & & & & & & \\
\hline JUNE & & & & & & \\
\hline JULY & & & & & & \\
\hline$A \cup G$. & & & & & & \\
\hline SEPT. & & & & & & \\
\hline OCT. & & & & & & \\
\hline NOV. & & & & & & \\
\hline DEC. & & & & & & \\
\hline
\end{tabular}




\section{Energy Conservation Checklist and Building Survey Forms}

\section{Building Exterior}

Walls

Roof

Windows, Skylights

Entry Ways

Exterior Lighting

\section{Building Interior}

Walls
Type of surface (good condition? airtight?)

Color of surface (light to reflect summer heat?

Trees, bushes, plantings (used to shade building in summer)

Type and condition of surface (good condition? airtight?)

Color of surface (light color, reflective)

Ventilators (existing? adjustable?)

Shading, shielding (reflective film or outside shading best)

Condition (glass clean, unbroken, tight, unobstructed)

Opened/closed (open for ventilation in summer, closed in winter)

Doors (should be closed when heating or cooling)

Loading docks (doors into heated space closed, or seals around trucks; automatic or remote controls)

Floodlighting (not excessive; off during daylight; use automatic controls)

Signs (off during daylight; use automatic controls)

Type and condition of surface (good condition, easy to clean)

Color of surface (light colors)

Insulation (generally, the more the better 
if the building is heated or cooled)

Ceiling

Windows, Skylights

Doors

\section{Lighting}

Switching and Controls

Lamps
Type and condition of surface (good condition, easy to clean)

Color of surface (light colors)

Insulation (generally, the more the better if the building is heated or cooled)

Utilized for light (clean, unobstructed)

Heat loss and gain (same as outside; possibility of double glazing)

Infiltration (tight fit, caulking, latches function)

Automatic closing (between conditioned and unconditioned spaces)

Insulation (possible on large doors)

Infiltration (weather stripping)

Manual wall switches (many buildings have no provision for local control of lighting)

Automatic time switches (photocells or time switches can control inside lighting as well as outside lights)

Multiple level switches (to dim lights or turn off part of the lights when higher lighting intensity is not necessary)

Flexibility (to turn off lights whenever they are not needed)

To utilize daylight (wherever and whenever possible)

Type (incandescent, fluorescent, mercury; 
Fixtures

Lighting General can more efficient type of light be used?)

Efficiency (lumens/watt; can more efficient type of same light source be used?)

Burned-out lamps (fluorescent and mercury fixtures with burned-out lamps still use energy; age-blackened lamps are very inefficient since they give so little light)

Condition of reflectors (clean fixtures are more efficient light sources)

Condition of lenses (clean, unbroken)

Position (spacing, height, orientation; is it possible to relocate fixtures over task area?)

Overall lighting levels (adequate but not excessive)

Supplementary or task lighting (on only when necessary)

Security/safety lighting (not excessive, on only when necessary)

Group relamping, maintenance (good maintenance gives higher light and output for energy used)

\section{Heating, Ventilating, Air Conditioning (HVAC)}

Thermostats, Controls

Time clocks (check for proper operation)

Proper location (poorly located thermostats can cause false indications and excessive energy usage)

Setting spread $\left(68^{\circ}\right.$ heating, $78^{\circ}$ cooling; $10^{\circ}$ spread can save one-fourth to one-third energy)

Heating/cooling interlocks (in many cases, heating bucks cooling due to improper controls)

Off-hour setback (or off) (maintain comfort 


\section{Heating Equipment}

Ventilation

(Air Handling) conditions only during necessary hours)

Security locks (lock thermostats and controls to prevent readjustment)

Economizer cycle (cool building with outside air when possible; prevents control overshoot)

Variable morning warm-up (on warmer mornings building warm-up can be started later and still make the building comfortable by building opening time)

Properly adjusted (to highest efficiency)

Properly sized (oversized or undersized equipment will not function as efficiently)

Adjustable temperatures (can temperatures of delivered air/water be adjusted to minimums?)

Operation when not needed (temperature lockout - interlock prevents overheating areas)

Waste heat reclamation (use of heat exchangers)

Use of infrared (can IR be used for spot heating rather than forced air for space heating?)

Minimum makeup air (heating or cooling makeup air is expensive)

Air leaks (is duct work tight? leaks waste energy)

Filters (clean; proper porosity for fan system?)

Insulation (is duct work insulated in nonconditioned spaces or areas where temperatures could be different?)

Variable speed fans (slow fans when maxi- 
mum air is not required)

Exhaust fans (running only when necessary)

Conditioned air to unoccupied areas (direct conditioned air only to occupied areas)

Dampers and controls (are they functional and properly controlled and adjusted?)

Double duct systems (energy wasteful if not properly instrumented, controlled, and adjusted)

Zone control (are zones properly arranged to fit operation of building?)

\section{Air Conditioning}

Properly adjusted (to manufacturer's specifications)

Properly sized (oversized or undersized equipment will be inefficient)

Adjustable temperatures (so that air is cooled no more than necessary)

Operation when not needed (temperature lockout - interlock prevents overcooling areas)

Waste heat reclamation (through use of double bundle condensers and heat exchangers)

Routine cleaning of coils (for maximum heat transfer)

Cooling tower maintenance and adjustment (if appropriate for maximum heat transfer)

Unnecessary humidity loads (dehumidification is expensive; consider exhaust hoods)

Precooling (condenser air or makeup air) evaporative cooling, dry cooling, and heat exchangers can cut down on compressor loads)

Refrigerant lines insulated (energy lost in refrigerant lines cannot cool the building) 
Building Operation
Morning warm-up (cool down) minimized (mild weather startup can be much shorter than extreme weather lead-time)

Minimum elevator use, off-hours (can some be shut down?)

Janitorial service during working hours (how much can be done during normal hours; trash collection?)

Coordination of after-hours janitorial services (minimize the time lights are on)

Drawing draperies or blinds (reduce heat loss at night)

Doors closed (during normal hours to reduce heat transfer)

Flywheel effect of heating/cooling (can equipment be shut off before building closes?)

Weekend partial operation (can building be zoned so that only that portion of building in use is heated/cooled)

Off-hours ventilation (minimized or off)

Exhaust fans (minimize use)

Hot water to restrooms (can temperature be reduced?)

Refrigerated drinking fountains (turned off during off-hours)

Uninsulated hot/cold water lines (can they be insulated?)

Leaking faucets, valves, steam traps (repair)

Equipment (Xerox, typewriter, etc.) running when not in use)

Convert in-plant electric distribution system to higher voltage or frequency (generally, higher voltages or frequencies 
will increase efficiency)

Power factor improvement (can reduce inplant energy losses)

Waste heat storage (hot water tanks) (can it be stored and used later?)

Spot infrared heating rather than general heating in hi-bay and production areas (heat only the personnel; considerable savings can be accrued)

Train maintenance personnel in efficient operation of building (controls and equipment are not effective unless operating personnel understand how to utilize them efficiently)

Equipment running when not in use (can it be turned off?)

Supplemental lighting on when not in use (can it be turned off?)

Supplemental equipment on when not in use (can it be turned off?)

Under part-load conditions, put all load on one boiler rather than part load on several boilers; boilers are generally more efficient when operating near full load)

Motors properly sized (operate more efficiently)

Train employees in efficient operation of equipment and processes (no equipment is better than the operator; employee understanding and training is a must)

Boiler economizers (add on) (if stack temperatures are high enough, a boiler economizer can recapture considerable energy) 


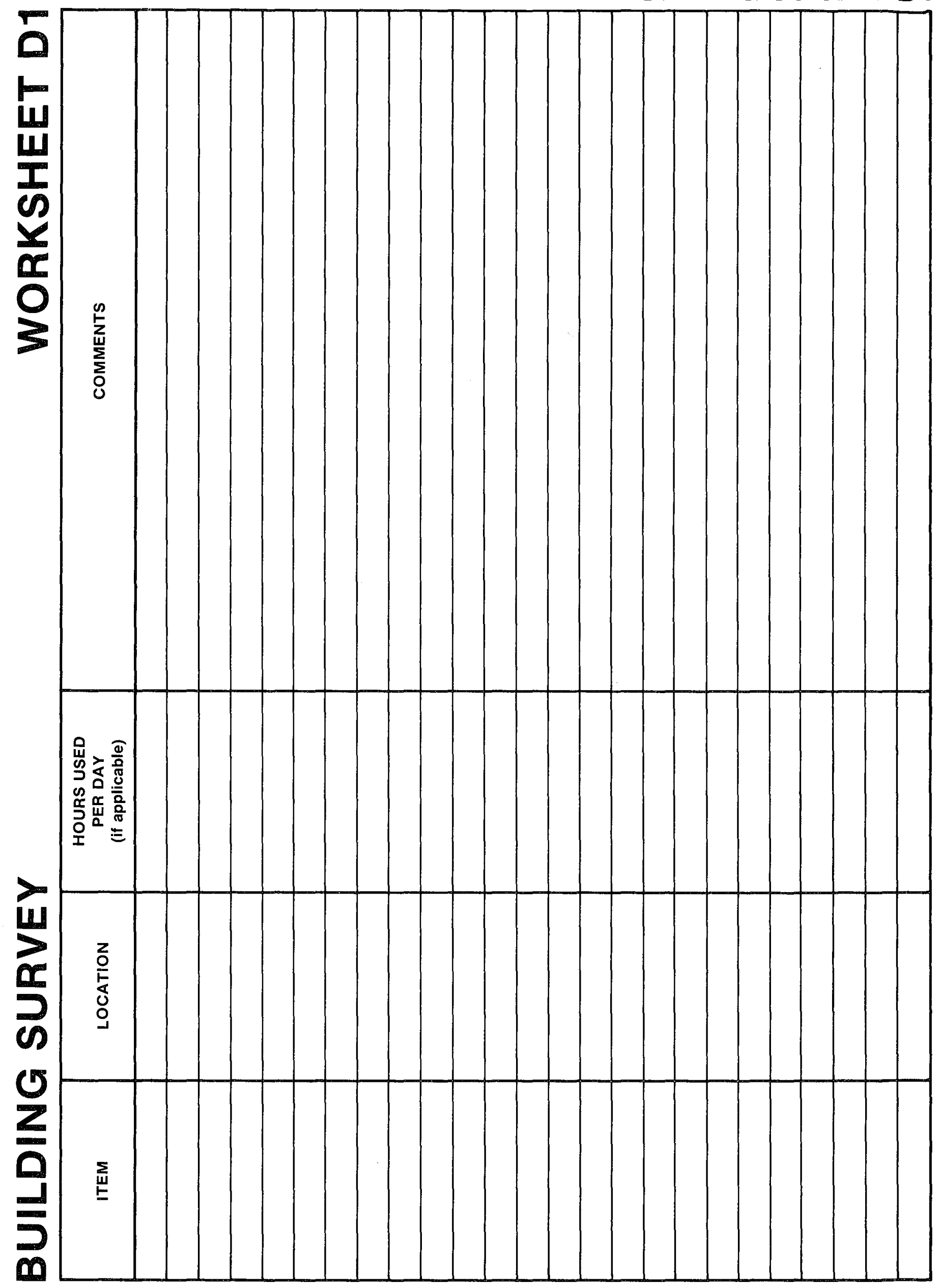




\section{Conducting a Lighting Survey}

STEP ONE. Using a simple pocket light meter, measure the illumination levels of all rooms or of each typical room. Take readings at the center of the room, near the windows, and along the walls. To allow an accurate comparison with the illumination levels recommended by the Illuminating Engineering Society (IES) (listed below), readings should be taken 30 inches above the floor and 30 inches away from the walls.

STEP TWO. Try to determine the age of the bulbs. Older bulbs provide less illumination and will give an inaccurate indication of the adequacy of lighting levels.

STEP THREE. Compare the illumination levels in your building with the recommended levels given below. If the levels vary significantly, consider replacing some of your lamps or fixtures. The "Lamp Characteristics" section will assist you in identifying the most appropriate type of lamp for your application. 


\section{RECOMMENDED LIGHTING LEVELS}

The Illuminating Engineering Society recommends the following lighting levels for various uses and occupancies:

\section{ILLUMINATION LEVELS}

Minimum Foot Candles

\section{Libraries}

Reading rooms and carrels …...........................70

Stacks ............................................................... 30

Book Repair and Bindings ................................... 70

Check in \& out, catalogs, card files..................... 50

\section{Offices}

Designing, detailed drafting

Accounting, bookkeeping and

business machines....................................... 85

Regular office work, reading, transcribing,

active filing and mail sorting.............................. 70

Corridors and stairways ........................................ 20

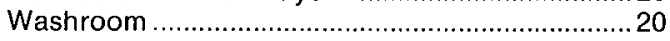

\section{Classroom Space}

Regular classroom work.....................................50

Chalk boards.................................................... 100

Drafting rooms

\section{Auditorium}

Assembly only 20

Study hall 50

The variations in intensity measured in lumens / watt for different lamp types are as follows:

\section{Lamp Type}

Incandescent

Fluorescent

Mercury

Metal Additive

Hi Pressure Sodium
Intensity

16-20 lumens/watt 60 lumens/watt 60 lumens/watt 43 lumens/watt 95 lumens/watt
Translated into gallons of fuel oil per year these intensity ratings used the following in a typical laboratory of 100,000 s.f. operating 3,000 hours/year:

$\begin{array}{lr}\text { Lamp Type } & \text { Fuel Oil Consumption per year } \\ & \\ \text { Incandescent } & 100,000 \text { gallons } \\ \text { Mercury } & 46,000 \text { gallons } \\ \text { Metal Additive } & 34,000 \text { gallons } \\ \text { Fluorescent } & 30,000 \text { gallons } \\ \text { Hi Pressure Sodium } & 22,000 \text { gallons }\end{array}$


EQUIPMENT SURVEY: LIGHTING

\begin{tabular}{|c|c|c|c|c|}
\hline $\begin{array}{l}\text { EQUIPMENT } \\
\text { ITEM \& } \\
\text { LOCATION }\end{array}$ & 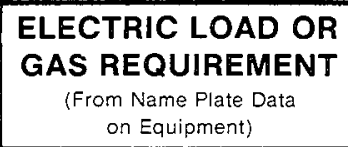 & $\begin{array}{l}\text { HOURS USED } \\
\text { PER DAY }\end{array}$ & $\begin{array}{l}\text { ILLUMINATION } \\
\text { READING } \\
\text { (Foot Candles) }\end{array}$ & COMMENTS \\
\hline \multicolumn{5}{|l|}{ Exterior Lighting } \\
\hline & & & & \\
\hline & & & & \\
\hline & & & & \\
\hline & & & & \\
\hline & & & & \\
\hline & & & & \\
\hline & & & & \\
\hline & & & & \\
\hline & & & & \\
\hline Interior Lighting & & & & \\
\hline & & & & \\
\hline & & & & \\
\hline & & & & \\
\hline & & & & \\
\hline & & & & \\
\hline & & & & \\
\hline & & & & \\
\hline & & & & \\
\hline & & & & \\
\hline & & & & \\
\hline & & & & \\
\hline & & & & \\
\hline & & & & \\
\hline & & & & \\
\hline
\end{tabular}

WORKSHEET D2 


\section{EQUIPMENT SURVEY: HVAC}

WORKSHEET D3

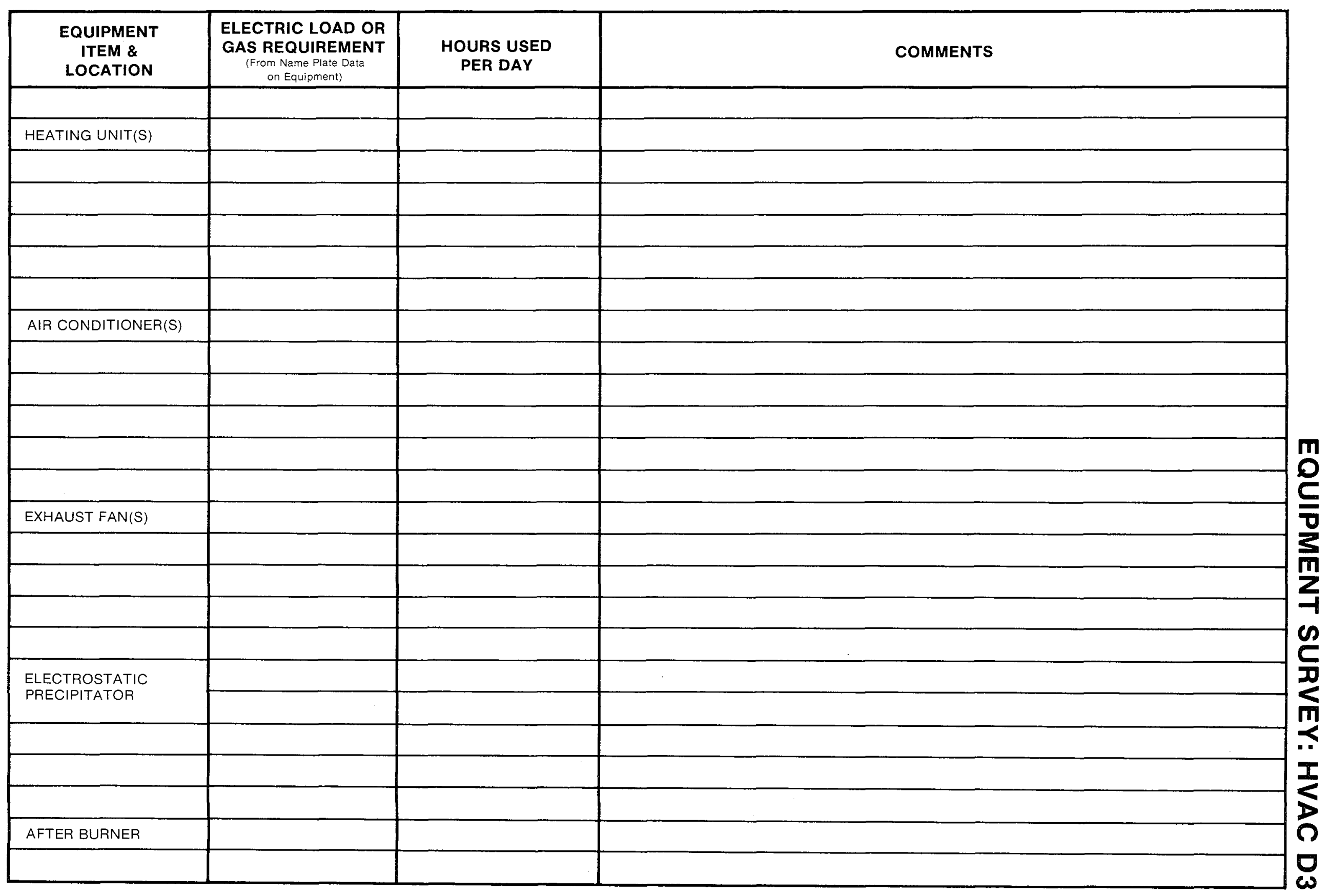




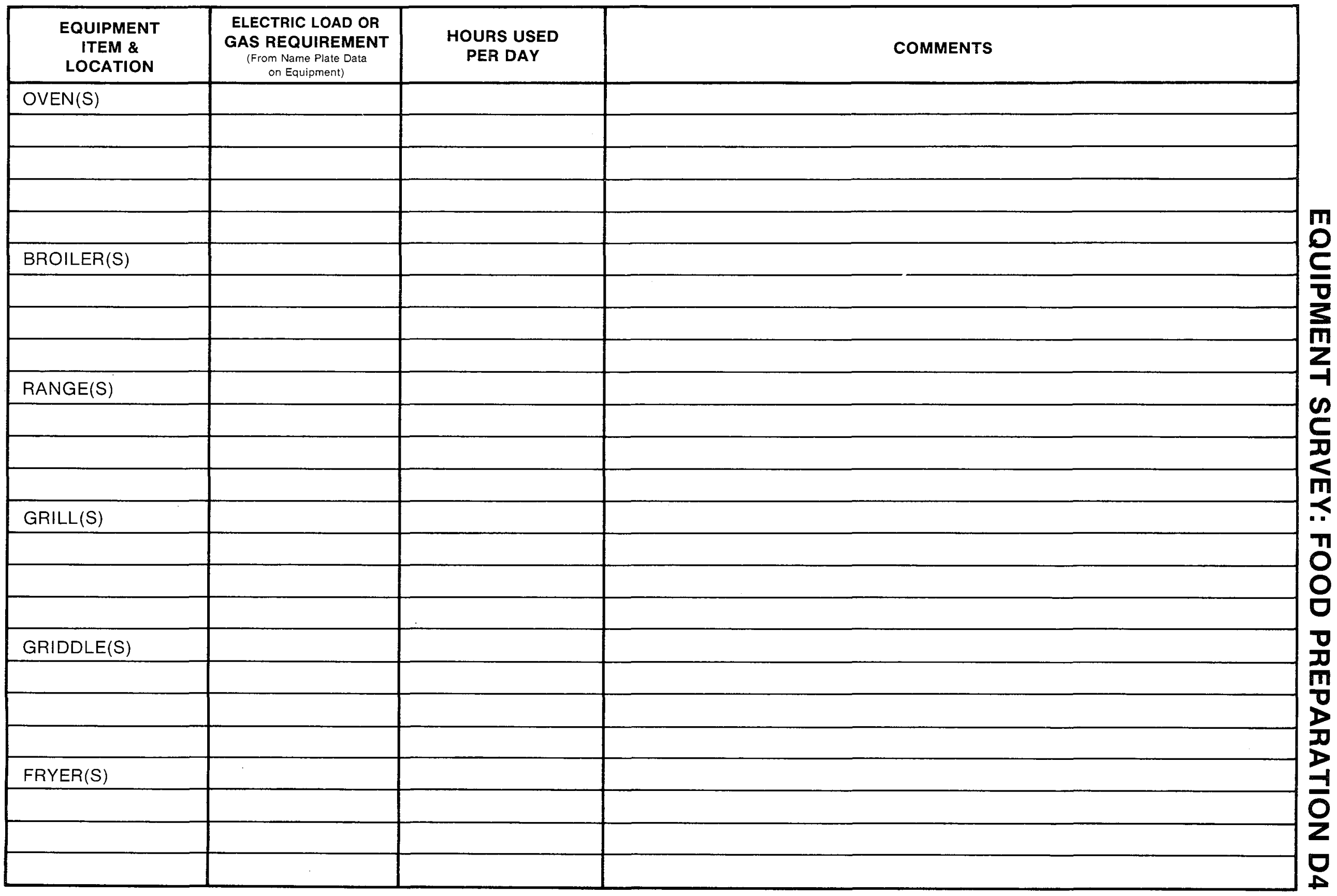




\section{EQUIPMENT SURVEY: FOOD PREPARATION}

WORKSHEET D6

\begin{tabular}{|c|c|c|c|}
\hline $\begin{array}{l}\text { EQUIPMENT } \\
\text { ITEM \& } \\
\text { LOCATION }\end{array}$ & 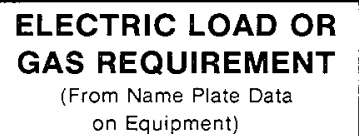 & $\begin{array}{l}\text { HOURS USED } \\
\text { PER DAY }\end{array}$ & Comments \\
\hline \multicolumn{4}{|l|}{ MISCELLANEOUS } \\
\hline & & & \\
\hline & & & \\
\hline & & & \\
\hline & & & \\
\hline & & & \\
\hline & & & \\
\hline & & & \\
\hline & & & \\
\hline & & & \\
\hline & & & \\
\hline & & & \\
\hline & & & \\
\hline & & & \\
\hline & & & \\
\hline & & & \\
\hline & & & \\
\hline & & & \\
\hline & & & \\
\hline & & & \\
\hline & & & \\
\hline & & & \\
\hline & & & \\
\hline
\end{tabular}




\section{EDUCATIONAL PLANT USAGE SCHEDULE}

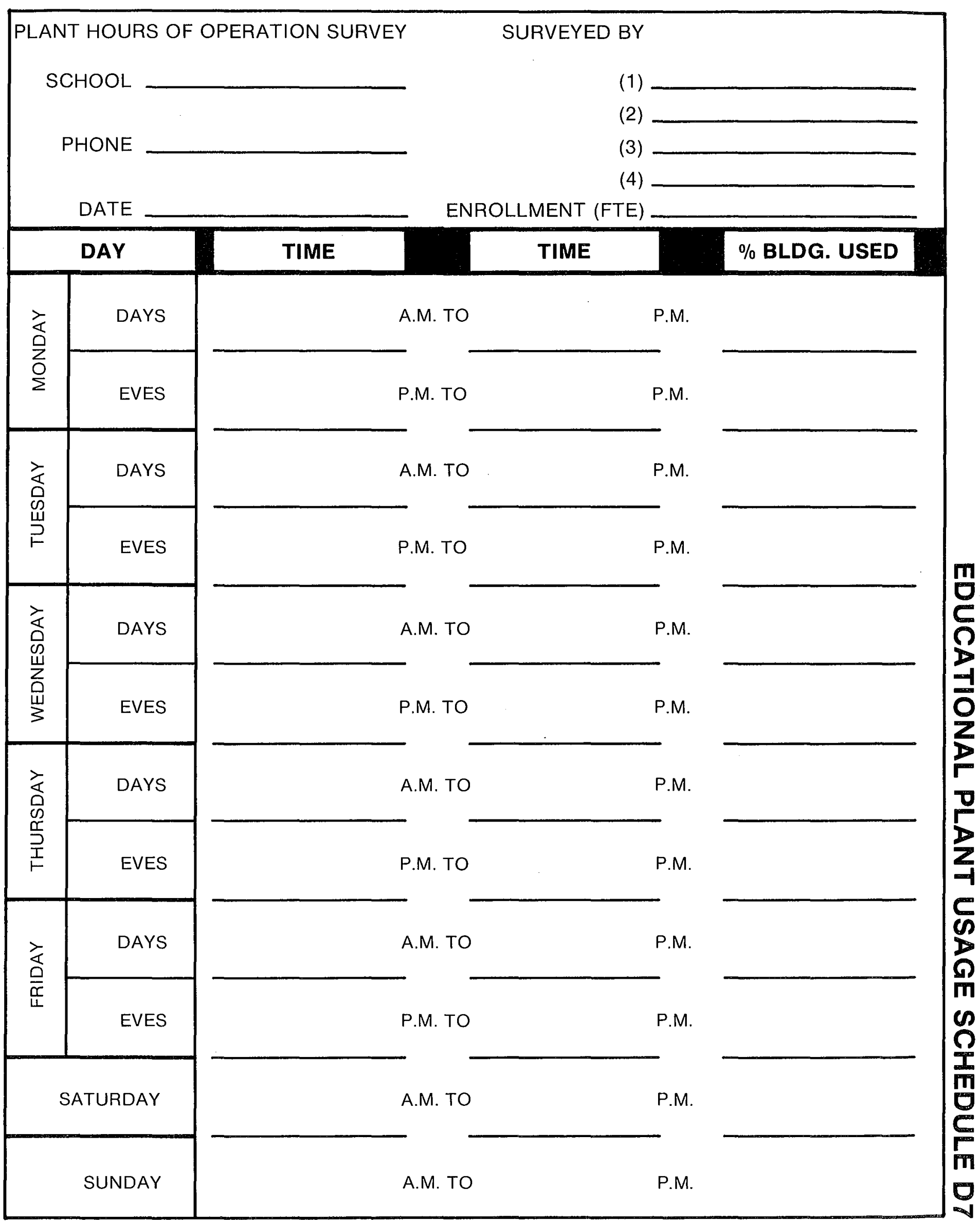




\section{Lighting}

Lighting costs can be reduced by up to $30 \%$ without making a substantial capital investment. Although lighting costs may constitute a relatively small portion of a facility's energy budget, lighting conservation can provide immediate energy and dollar savings.

The aim of any lighting conservation program should be to provide adequate illumination at the least possible energy cost. It will therefore be necessary to understand lighting efficiencies; that is, the amount of light given off in relation to the amount of energy used. The efficiency of a lamp (bulb) is essentially the amount of illumination provided in relation to the amount of electricity used. Since the amount of illumination declines as the bulb is used, its efficiency is influenced by its lifespan.

Light bulbs are measured by the following units: lumens for light output; watts for electricity used; and hours for bulb lifetime. This information, found on the package of the bulb, will enable you to compare bulb efficiencies. For your convenience, a comparative table has been included in this section.

Lighting energy conservation must be achieved in a manner that is consistent with the functions of the building and the needs of its users: visual comfort, safety; security; aesthetics; and federal, state and local codes. In addition, since even the most efficient light bulb converts only $25 \%$ of the energy it uses to light and gives off the other $75 \%$ as heat (incandescent bulbs, which are the least efficient type, give off $90 \%$ of the energy as heat), reducing the number of lights will likely have an effect on heating and cooling systems (which were probably designed to consider that "heat of light").

The following pages will outline some actions which will, if taken, constitute an effective lighting management program.

\section{Lighting Schedule}

A logical first step in any lighting management program is the development of a schedule for lighting control which will ensure that lights are turned on only when and where they are needed. Personnel should be assigned to and made responsible for the efficient utilization of lighting. Detailed instructions for the operation of lighting systems, in the form of charts and color coding of switches, should be provided. A small sign near each switch should show which lights are controlled by that switch. This identification will reduce the energy wasted by trialand-error switching of lights on and off. In addition, the users should be provided with a reminder to turn lights off whenever they are not being used. 


\section{Maintenance}

Because lamp efficiency declines with use, illumination level checks should be made part of routine maintenance. When the output of a bank of lights falls to $70 \%$ of its original level, the bulbs of all the fixtures in that bank should be replaced with the most efficient lamp that is suitable.

To provide maximum illumination, the reflecting surfaces and shields of all lighting fixtures should be cleaned regularly. Lens shields which have yellowed should be replaced.

Ceilings, walls, and floors should be kept as clean as possible to maintain their reflective properties. When repainting walls and ceilings, consider using lighter colors which reflect more light. Clean windows will also help to reduce the need for supplemental lighting during the day time.

\section{Lamp Modifications}

In those areas which have been identified as having illumination levels higher than necessary, consider eliminating some lamps or replacing them with more efficient bulbs. In some cases, a change to a more efficient type of lamp will justify the expense of the necessary change of fixture.

Removal of unnecessary lamps if done correctly, can be an easily implemented energy saving measure. Fixtures should be removed from behind, rather than in front of, task areas, as front lighting keeps task areas free of shadows. The primary of the ballast (ballasts are small boxes within the fluorescent fixture which are used to start the lamps) serving the lamps which are being removed should be disconnected by an electrician to avoid continued energy drain from an unused ballast. When removing tubes from fixtures holding four fluorescent tubes, remove two from each fixture rather than all the tubes from alternate fixtures. In this manner, even lighting levels can be maintained throughout the space.

Replacement of existing lamps with more efficient ones (those giving the same illumination but using fewer watts) should be considered. Lowering fixtures or replacing lenses may allow the use of lower wattage lamps yet provide the same effective illumination. Care should be exercised to ensure that new lamps are compatible with existing ballasts. Wherever possible, replace two bulbs with one which provides a comparable number of lumens. 
Relocating fixtures to provide task-oriented illumination, rather than uniformly illuminating an entire area, may allow the elimination of some lamps.

When old or damaged fixtures are replaced, consider using higherefficiency lamps which provide more constant illumination levels for a longer time and use less energy.

Multiple level ballasts and dimming controls should be considered for multipurpose spaces which require differing levels of illumination.

Special lenses which provide more effective light distribution patterns may provide improved illumination while using the same amount of or, in some cases, less energy.

\section{Control Modifications}

Photocells can be used to switch off banks of lights when their use is made unnecessary by an increase in natural lighting. In addition, certain exterior areas that require lighting all night for security should be controlled by photocells to ensure that they are turned off promptly at daybreak.

Timing mechanisms may be warranted for controlling exterior lights that are needed for only a part of the period of darkness. Such mechanisms should also be considered for use in interior areas that require lighting only for brief periods.

Dimmers or alternative switching should be considered for areas that require different levels of light at different times.

Automatic switches, which turn lights on when doors are opened, are efficient for rooms which are used infrequently and for short periods of time, such as storage rooms.

\section{Lamp Characteristics}

The choice of lamp type will be determined by a combination of factors. The information provided in the following pages will assist you in identifying the most efficient type that will be suitable for each area. 


\section{E Continued}

\section{Incandescent}

Incandescent lamps are the most commonly used for indoor lighting. However, they are also the least efficient. Light is produced by heating a tungsten filament inside the bulb until it glows, but $90 \%$ of the energy is converted to heat by this process. This heat burdens the air conditioning system in summer and is an expensive way to heat in winter.

"Long-life" incandescent bulbs are designed to burn for 2, 3, or 5 years. Since they are expensive and inefficient in comparison with any other lamp of the same wattage, they are recommended only where lighting maintenance is irregular or difficult and where incandescence is desirable.

Another type of incandescent bulb, known as tungsten halogen, is filled with a class of chemicals called halogens. Although no more efficient than an ordinary incandescent bulb, the tungsten halogen retains its illuminating ability far longer.

PAR (parabolic aluminized reflector) lamps have an interior coating of aluminum, which reflects light toward the front of the bulb. They are commonly used as flood or spotlights for specific areas, such as displays, and are effective "cool" beam lighting. PAR lamps are manufactured either with standard incandescent filaments or with long-life tungsten halogen filaments.

\section{Fluorescent}

Fluorescent lamps, which are also commonly used indoors, are far more efficient than standard incandescent lamps. Because they transfer more energy into light and less into heat, fluorescent lamps are approximately four times as bright as incandescent lamps of the same wattage.

Ordinary fluorescent lamps are, however, undesirable in many areas because of their cool, bluish color and flat illumination. The color-corrected lamps available have been made "warm" by the addition of red tint to the bulb coating. However, $25 \%$ to $30 \%$ of the illumination has been sacrificed. Normally, "cool white" and "warm white" lamps have the highest illumination per watt of input energy, followed by deluxe and color-corrected lamps. Fluorescent lamps are usable just about any place an incandescent lamp is, except in those areas where aesthetic concerns for shape and illumination cannot be satisfied.

The several-second delay in "start up" time is another drawback to fluorescent 
lamps. Although so-called "fast-start" lamps are available, they are more expensive and somewhat less efficient than standard fluorescent lamps.

\section{Neon}

Neon vapor lamps are tubes containing neon gas, which conducts an electric charge across the tube to create illumination. The range of colors associated with neon lighting is obtained by adding helium to the tube or by varying the gas pressure. Neon lamps are an inexpensive way to highlight signs or to add decorative outdoor lighting. However, their flat, washed-out color and relatively lowillumination make them inadequate illumination sources.

\section{Mercury}

Mercury lamps, which can be used indoors or out, are commonly used in parking areas and large industrial spaces. Their advantages are a low initial installation cost and a very long life with high lumen output. The bluish color of the mercury light has traditionally made it undesirable for general outdoor use. However, the recently developed "deluxe mercury" lamp has better color rendition. Another drawback is the 3 to 5 minute start-up time and the 5 to 10 minute time delay before restarting. "Deluxe mercury" lamps are suitable for kitchens, laundries, and other workrooms and utility areas, as well as outdoors.

In addition, special mercury lamps in low-watt sizes are now available to replace incandescent bulbs in interior fixtures. These lamps offer a long life with continuously high lumen output and excellent color. Their efficiency is approximately double that of ordinary incandescent bulbs, although only half that of fluorescent.

\section{Metal Halide}

Metallic halide lamps are widely used for outdoor floodlighting because of their good color rendition. However, the lifespan of this extremely efficient lamp is not as long as that of the mercury lamp, and its illumination declines more rapidly. Its excellent color makes it suitable for many outdoor uses.

\section{High-Pressure Sodium}

One of the newest and most promising lamps to be developed recently, and the most efficient on the market, the high-pressure sodium lamp is used for lighting streets and parking lots. It remains bright ( $80 \%$ of start-up illumination) until it burns out. However, its strong yellow light dulls, or "grays," the colors of red and blue objects. The high-pressure sodium lamp is the most suitable for brilliant outdoor lighting. 


\section{Types of Lighting Compared}

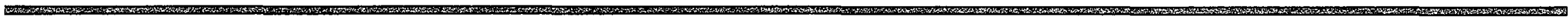

\begin{tabular}{|c|c|c|c|c|c|c|c|}
\hline $\begin{array}{l}\text { ype and } \\
\text { Vattage }\end{array}$ & $\begin{array}{l}\text { Lumens } \\
\text { Per Watt }\end{array}$ & Lifetime & $\begin{array}{l}\text { Lumen } \\
\text { Efficiency }\end{array}$ & $\begin{array}{l}\text { Equipment } \\
\text { Cost }\end{array}$ & $\begin{array}{l}\text { Operating } \\
\text { Cost }\end{array}$ & Color Characteristics & Recommended Uses \\
\hline
\end{tabular}

(L/W)

\begin{tabular}{|c|c|c|c|c|c|c|c|c|c|}
\hline \multirow{5}{*}{$\frac{8}{80}$} & $\begin{array}{c}\text { Standard } \\
15 \\
25 \\
40 \\
60 \\
75 \\
100 \\
250 \\
500 \\
\end{array}$ & \begin{tabular}{c|}
8 \\
9 \\
9 \\
12 \\
14 \\
18 \\
18 \\
20 \\
21 \\
\end{tabular} & $\begin{array}{l}750- \\
1000 \text { hrs. } \\
\text { shortest } \\
\text { of all } \\
\text { lamps }\end{array}$ & $\begin{array}{l}80 \% \text { prior } \\
\text { to failure }\end{array}$ & Low & High & $\begin{array}{l}\text { - Nearest to natural daylight } \\
\text { Skin tones heightened. Gives } \\
\text { "warm" atmosphere where } \\
\text { used }\end{array}$ & $\begin{array}{l}\text { - Where lamps are burned } \\
\text { fewer than } 6 \text { hrs a day } \\
\text { "Where foot-candle require- } \\
\text { ments are under } 50 \text {. } \\
\text { - Where "warm" atmosphere } \\
\text { is desired }\end{array}$ & $\begin{array}{l}\text { - Efficiency is critically } \\
\text { dependent on operating } \\
\text { voltage. Do not burn lamps } \\
\text { at voltages lower than the } \\
\text { output of the electrical } \\
\text { socket }\end{array}$ \\
\hline & $\begin{array}{l}\text { Long-life } \\
100\end{array}$ & & $\begin{array}{l}2,3, \text { or } \\
5 \text { years }\end{array}$ & & High & High & & $\begin{array}{l}\text { - Only where maintenance is } \\
\text { difficult or irregular }\end{array}$ & \\
\hline & $\begin{array}{l}\text { PAR } \\
250\end{array}$ & 18.4 & & $\begin{array}{c}\text { Reduced to } \\
70 \% \text { after } \\
1,000 \mathrm{hrs} .\end{array}$ & & & & $\begin{array}{l}\text { - As narrowbeam flood- } \\
\text { lights } \\
\text { "Cool beam" lamps suitable } \\
\text { for displaying food }\end{array}$ & \\
\hline & $\begin{array}{c}\text { Tungsten Halog } \\
45 \\
100 \\
150 \\
200 \\
250 \text { Spot } \\
500 \text { Spot } \\
1,000 \text { Flood } \\
\end{array}$ & $\begin{array}{l}13 \\
18 \\
18 \\
19 \\
13 \\
14 \\
17 \\
\end{array}$ & $\begin{array}{l}4,000 \text { hrs. } \\
\text { minimum } \\
\text { for high- } \\
\text { voltage } \\
\text { lamps }\end{array}$ & $\begin{array}{l}90 \% \text { after } \\
3,000 \text { hrs. }\end{array}$ & Low & Low & $\begin{array}{l}\text { - Good color rendition: } \\
\text { bright, white }\end{array}$ & $\begin{array}{l}\text { - Where strong light is desired } \\
\text { - Where good color is desired } \\
\text { - General lighting for large } \\
\text { rooms, production areas } \\
\text { - In cornices and niches }\end{array}$ & $\begin{array}{l}\text { - Low wattages available for } \\
\text { single-purpose lamps } \\
\text { - Not as flexible as standard } \\
\text { incandescent } \\
\text { - Significant savings in energy } \\
\text { and costs over standard incan- } \\
\text { descent }\end{array}$ \\
\hline & $\begin{array}{c}\text { PAR } \\
150\end{array}$ & & & $\begin{array}{l}98 \% \text { after } \\
3,000 \text { hrs. }\end{array}$ & & & & $\begin{array}{l}\text { - For floodlighting and out- } \\
\text { door decorative lighting }\end{array}$ & \\
\hline 8 & $\begin{array}{c}40 \\
60 \\
75 \\
110\end{array}$ & $\begin{array}{l}66 \\
68 \\
73 \\
72\end{array}$ & $20,000 \mathrm{hrs}$. & $\begin{array}{c}70 \% \text { at } \\
12,000- \\
15,000 \mathrm{hrs} .\end{array}$ & $\begin{array}{l}\text { Higher } \\
\text { than } \\
\text { incand- } \\
\text { escent }\end{array}$ & $\begin{array}{l}\text { Lower } \\
\text { than } \\
\text { incand- } \\
\text { escent }\end{array}$ & $\begin{array}{l}\text { - Cool white has the poorest } \\
\text { color rendition; warm and deluxe } \\
\text { warm white are better. Deluxe } \\
\text { warm white most closely approx- } \\
\text { imates natural daylight }\end{array}$ & $\begin{array}{l}\text { - In production areas, kitchens, } \\
\text { offices } \\
\text { - As display lighting } \\
\text { - Deluxe cool white, deluxe } \\
\text { warm, and white can be usually } \\
\text { used in place of incandescent } \\
\text { bulbs }\end{array}$ & $\begin{array}{l}\text { - Ballasts required for start-up } \\
\text { reduce lamp efficiency } \\
\text { - Color-corrected lamps are } \\
\text { 30\% less efficient than standard } \\
\text { - Efficiency especially affected } \\
\text { by ambient temperature } \\
\text { - Cool and warm white have } \\
\text { highest outputs, followed by } \\
\text { deluxe and color-corrected } \\
\text { lamps }\end{array}$ \\
\hline
\end{tabular}




\section{Types of Lighting Compared}

\begin{tabular}{|c|c|c|c|c|c|c|c|c|c|}
\hline & $\begin{array}{l}\text { Type and } \\
\text { Wattage }\end{array}$ & $\begin{array}{l}\text { Lumens } \\
\text { Per Watt } \\
\text { (L/W) }\end{array}$ & Lifetime & $\begin{array}{l}\text { Lumen } \\
\text { Efficiency }\end{array}$ & $\begin{array}{l}\text { Equipment } \\
\text { Cost }\end{array}$ & $\begin{array}{l}\text { Operating } \\
\text { Cost }\end{array}$ & Color Characteristics & Recommended Uses & Remarks \\
\hline \multirow{3}{*}{$\frac{8}{80}$} & $\begin{array}{l}\text { Mercury } \\
40 \\
100 \\
175 \\
250 \\
400\end{array}$ & $\begin{array}{l}29 \\
41 \\
42 \\
46 \\
51\end{array}$ & 24,000 hrs. & $\begin{array}{c}75 \% \text { after } \\
16,000 \text { hrs. }\end{array}$ & Low & Medium & $\begin{array}{l}\text { - Available in clear, white, } \\
\text { color-corrected, and deluxe } \\
\text { white. Deluxe white has best } \\
\text { color rendition } \\
\text { - Deluxe white is interchange- } \\
\text { able with cool white fluorescent }\end{array}$ & $\begin{array}{l}\text { - Indoors to light large spaces } \\
\text { such as kitchen and production } \\
\text { areas } \\
\text { Outdoors in parking areas } \\
\text { and as merchandising or decor- } \\
\text { ative lighting }\end{array}$ & $\begin{array}{l}\text { - Cannot be dimmed; voltage } \\
\text { requirements are precise } \\
\text { - Not as sensitive to frequent } \\
\text { start-ups as fluorescent }\end{array}$ \\
\hline & $\begin{array}{c}\text { Special Mercury } \\
40 \\
75 \\
100\end{array}$ & $\begin{array}{l}18 \\
36 \\
36\end{array}$ & 24,000 hrs. & $\begin{array}{l}75 \% \text { after } \\
16,000 \text { hrs. }\end{array}$ & Low & Medium & $\begin{array}{l}\text { - Excellent color; preferred } \\
\text { alternative to cool white } \\
\text { fluorescent } \\
\text { - Second best color choice for } \\
\text { "warm" atmosphere }\end{array}$ & $\begin{array}{l}\text { - Can replace incandescent } \\
\text { lamps in interior fixtures }\end{array}$ & $\begin{array}{l}\text { - Limited number of sizes; } \\
\text { strictly for interior fixtures } \\
\text { - Higher wattages and longer } \\
\text { life than standard mercury }\end{array}$ \\
\hline & $\begin{array}{l}\text { Metal Halide } \\
175 \\
250 \\
400\end{array}$ & $\begin{array}{l}70 \\
64 \\
80\end{array}$ & $\begin{array}{l}7,500- \\
15,000 \text { hrs. }\end{array}$ & $\begin{array}{l}60 \% \text { after } \\
11,000 \text { hrs. }\end{array}$ & Medium & Medium & $\begin{array}{l}\text { - Better color than mercury; } \\
\text { not as good as special mercury } \\
\text { - Color-coated bulb has good, } \\
\text { warm color; clear bulb less } \\
\text { satisfactory } \\
\text { - Best color rendition for } \\
\text { outdoor lighting }\end{array}$ & $\begin{array}{l}\text { - Parking areas } \\
\text { - Large work spaces } \\
\text { - Interior spaces lighted } \\
\text { from above } \\
\text { - Food displays }\end{array}$ & $\begin{array}{l}\text { - Ballast required } \\
\text { - Higher lumen output, lower } \\
\text { lifetime than mercury }\end{array}$ \\
\hline$\frac{1}{5}$ & $\begin{array}{l}\text { High-pressure } \\
\text { Sodium } \\
150 \\
250 \\
400\end{array}$ & $\begin{array}{c}89 \\
80 \\
106\end{array}$ & $\begin{array}{l}12,000 \mathrm{hrs} \\
15,000 \mathrm{hrs} \\
20,000 \mathrm{hrs}\end{array}$ & $\begin{array}{l}80 \% \text { at end } \\
\text { of lifetime }\end{array}$ & High & Low & $\begin{array}{l}\text { - Poor color rendition; grays } \\
\text { colors of red and blue objects, } \\
\text { Similar to warm white fluor- } \\
\text { escent }\end{array}$ & $\begin{array}{l}\text { - Outdoor, where color is un- } \\
\text { important: in parking spaces and } \\
\text { - If illumination of building is } \\
\text { enhanced by yellow light }\end{array}$ & $\begin{array}{l}\text { - The most efficient lamp } \\
\text { currently on the market }\end{array}$ \\
\hline
\end{tabular}

NOTES: Neon lights have not been included because they are commonly used only as decorative lighting Fluorescent lamps described are all "rapid start."

Lumen efficiencies and numbers of lumens per watt are approximations. 


\section{Outdoor Lighting Levels}

To determine the amount of outdoor lighting needed for your building or parking lot, use the "Outdoor Lighting Table" below. The table recommends appropriate illumination and wattage per square foot of space.

In order to calculate your present outdoor wattage for comparison with the recommended wattage in the table:

1. Add the total number of watts being used to light the space:

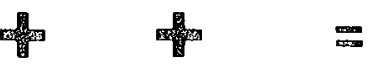

2. Determine the square footage of the surface being lighted. To do so, you merely multiply the length of the space (in feet) by the width of the space (in feet):

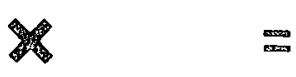

3. Divide the number of watts by the number of square feet to get the watts used per square foot:

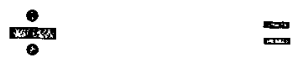

4. Compare this number with the number in the table to determine the best equipment and application:

$\infty$

\section{Outdoor Lighting Table}

\begin{tabular}{|c|c|c|c|c|c|c|c|c|c|c|c|c|}
\hline & $\begin{array}{l}\text { Minim } \\
\text { Foot } \mathrm{Ca}\end{array}$ & & & & & & $\begin{array}{l}\text { Watts } \\
\text { Square }\end{array}$ & & & & & \\
\hline & & & Incande & scent & $\begin{array}{l}\text { Tungs } \\
\text { Halo }\end{array}$ & $\begin{array}{l}\text { gten, } \\
\text { gen }\end{array}$ & Merc & & Fluores & $8 c e n t$ & $\underset{\text { Sodiu }}{H-F}$ & \\
\hline arking Lots & & & & & & & & & & & & \\
\hline Attended & 2 & & 0.44 & & 0.38 & & 0.22 & & 0.24 & & 0.15 & \\
\hline Unattended & 1 & & 0.15 & 0.22 & 0.13 & -0.15 & 0.06 & 0.11 & $0.06-$ & -0.08 & $0.04-$ & 0.08 \\
\hline $\begin{array}{l}\text { Protective Lighting } \\
\text { Gates and vital areas }\end{array}$ & 5 & & 1.4 & & 1.2 & & 0.8 & & 1.5 & & 0.5 & \\
\hline Building surrounds & 1 & & $0.18-$ & 0.22 & 0.15 & -0.19 & 0.08 & 0.11 & 0.08 & -0.12 & $0.05-$ & 0.08 \\
\hline $\begin{array}{l}\text { Building Exteriors } \\
\text { (up to } 50 \text { feet high) }\end{array}$ & & & & & & & & & & & & \\
\hline $\begin{array}{l}\text { If adjacent area is: } \\
\text { Light surfaces }\end{array}$ & $\begin{array}{l}\text { light } \\
15\end{array}$ & $\begin{array}{l}\text { dark } \\
0.5\end{array}$ & $\begin{array}{l}\text { light } \\
3.8\end{array}$ & $\begin{array}{c}\text { derk } \\
1.4\end{array}$ & $\begin{array}{l}\text { light } \\
3.3\end{array}$ & $\begin{array}{c}\text { dark } \\
1.2\end{array}$ & $\begin{array}{l}\text { light } \\
2.4\end{array}$ & $\begin{array}{c}\text { dark } \\
0.8\end{array}$ & $\begin{array}{l}\text { light } \\
3.2\end{array}$ & $\begin{array}{c}\text { dark } \\
1.1\end{array}$ & $\begin{array}{l}\text { light } \\
1.6\end{array}$ & $\begin{array}{c}\text { dark } \\
0.5\end{array}$ \\
\hline Medium surfaces & 20 & 10 & 5.0 & 2.6 & 4.3 & 2.2 & 3.2 & 1.6 & 4.2 & 2.1 & 2.2 & 1.1 \\
\hline Dark surfaces & 50 & 20 & 12.0 & 5.0 & 10.0 & 4.3 & 8.0 & 3.2 & 10.5 & 4.2 & 5.4 & 2.2 \\
\hline and Signs & & 2 & & & 10 & & & & & & & 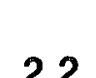 \\
\hline Poor contrast & 100 & 50 & 24.1 & 12.0 & 20.0 & 10.0 & 16.0 & 8.0 & 21.0 & 10.5 & 11.0 & 5.5 \\
\hline
\end{tabular}




\section{Heating, Ventilating, and Air Conditioning (HVAC)}

Heating, ventilating, and air-condition systems use a significant portion of the total energy used in most buildings. Significant energy savings can, therefore, be realized when HVAC systems are operated and maintained with energy efficiency in mind.

It is assumed here that the maintenance and operations engineer has established some routine maintenance schedules, and that HVAC systems are maintained by a competent maintenance staff. Nonetheless, there are some maintenance practices that might be overlooked unless energy efficiency is recognized as an important consideration. For example, outside air dampers that are not airtight are not a problem except in terms of the energy they waste. The following pages, then, contain some suggestions aimed at making the maintenance staff more aware of effective management of the energy used.

\section{Ventilation}

Keep outside air dampers closed during the first half-hour of heating or cooling system start-up. Buildings that have been empty for 12 hours or more are usually ventilated sufficiently by ordinary air leakage (infiltration). Outside air dampers should be closed when the building is unoccupied, and for the last hour of occupancy.

Reduce outside ventilation to the fewest air changes per hour that comfort and state and local codes will permit.

Check all outside air dampers regularly for air-tightness, as well as controls and position indicators for accuracy. Air baffles may be installed to block wind from blowing directly into outside air inlets.

Reduce exhaust air quantities wherever possible. Consider putting timers on exhaust fans to ensure that the exhaust system operates only when it is needed most.

Inspect air filters regularly. Clean or replace them as necessary.

Do not operate air handling units in rooms where doors or windows are open. 


\section{Infiltration}

Replace any cracked or broken window panes.

Caulk or weatherstrip all windows, sashes, frames, and outside doors. Replace weatherstripping that is cracked or worn.

Correct window or door misalignments.

Consider using signs to remind occupants to keep doors and windows closed when the heating or cooling system is in operation.

Consider double glazing (or adding storm windows), especially for windows on the north side.

\section{Boilers}

Eliminate as many boilers as possible, in a multi-boiler system, while maintaining proper space heat.

Keep boilers free from scale. Check all water-side surfaces, including the rear portion of the boiler. Consider chemical treatment of the boiler water to reduce scale.

Keep furnace (fire-side) free from soot deposits, flyash, and slag. A thermometer in the vent outlet will indicate the need for tube cleaning when the outlet temperature is abnormally high.

Maintain proper fuel/air ratio, as specified by the manufacturer, to ensure maximum combustion with minimum soot production.

Replace boiler door gaskets that do not provide a tight seal.

Close and cover baffles and vents on rooftop or window air conditioners during the heating season.

Maintain proper burner alignment and condition. Clean out burner nozzles and drain air tanks daily. Haze in the stacks usually indicates that the burner needs alignment.

Routinely check all boiler valves, controls, linkages, etc. for proper operation 
and movement.

Check boiler exterior and insulation for hot spots or air leaks.

If you are not already doing so, set up a daily log of boiler operating parameters, as indicated by instrumentation. Routine monitoring will give early indications of problems and abnormal variations, allowing maintenance and rectification before energy is wasted.

On fuel oil burners: Check for oil leaks; check oil line strainers and replace dirty ones; maintain fuel oil temperature at a burner tip according to specifications of the manufacturer (this will ensure proper viscosity and complete combustion, and reduce soot on heat transfer surfaces).

\section{Heat Exchangers}

All heat exchanger surfaces must be kept free of dirt, scale, or any other impediment to heat flow.

Be sure that room convectors, radiators, etc., are not blocked by obstructions; such as curtains or desks.

\section{Air Conditioning Equipment (Refrigeration)}

If you do not already have one, establish a routine maintenance schedule. Inspect the cooling system carefully for: oil or refrigerant leaks, moisture in the system, clogs in the strainer, proper belt alignment and tension, oil temperature and pressure, tightness of piping connections, and proper valve and control operation. Be sure to include inspection of fans, pumps, compressors, condensers, and all other equipment.

\section{Cooling towers}

Check water depth for evenness (in gravity fed towers)

Check nozzle in spray-filled towers

Check overflow pipe clearance

Check level of solid concentration (by chemical analysis)

Check fan, belts, alignments

Clean intake strainer 


\section{Air Handling Equipment}

Check ducts and duct insulation for air leakage

Check dampers, blades, valves, etc. for proper operation

Clean or replace air filters

Clean all diffusers, registers, and grills regularly

Clean nozzles on air washers or evaporative coolers

Replace filter media on electronic air cleaners

Lubricate bearings regularly and check drive belts for

alignment and tension

Clean fan screens

\section{Piping}

Check for worn, torn, or water-damaged insulation; replace as necessary

Check vents and strainers for clogs

Inspect valves and traps in steam lines for proper operation

\section{Controls}

HVAC systems should be balanced regularly to maintain an even distribution of thermal supply air and to avoid hot and cold spots

Control instruments should be checked and recalibrated regularly

Controls should be adjusted to prevent heating and cooling systems from operating at the same time

Check locations of thermostats to be sure they are not near drafts or exterior walls

Be sure that personnel responsible for setting temperatures on unit ventilators understand the difference between low limit settings and actual thermostat settings. Confusing these settings can cause overheating

Consider automatic timers to shut off equipment wherever practical 


\section{Building Envelope}

Some insulation can be retrofitted economically, without requiring extensive renovation. If insulation does not exist, it should be considered for roofs or top floor ceilings, exterior walls, and under floors. ASHRAE Standard 90-75 may be used as a reference for determining the appropriate levels of insulation.

Solar heat gain through windows can be useful in meeting some of the buildings' instantaneous heating loads. It can also add to the cooling load. Solar control films, which are applied directly to the glazing, should be considered where cooling loads are extreme. Interior shading devices can also be useful in reducing unwanted solar gain. Reflective materials on these inside shades can make them even more effective.

Storm windows, or double glazing, are often economically justifiable because of the energy savings which result from their insulative value.

\section{HVAC Operation}

Lower thermostats to $65^{\circ} \mathrm{F}$ in winter; raise them to $78^{\circ} \mathrm{F}$ in summer. Studies have shown that, when cooling, each degree the temperature is raised reduces electrical consumption by $5 \%$. When heating, each degree lowered reduces consumption by $3 \%$. Care should be taken, however, to avoid having the heating system come on and heat the space up to $78 \%$ in the summer when the temperature is less than $78^{\circ}$.

If these temperatures feel uncomfortable, check windows and doors for drafts; note the effect of heat from sunlit windows and interior lights.

To moderate the effects of these thermostat changes - or to allow greater reductions in heating and cooling-operate a dehumidifier instead of your cooling system in the summer. Dry air can be tolerated at higher temperatures than humid air. In the winter, the reverse is true-humidifying air will make it comfortable at lower temperatures. The energy costs of humidifiers are generally lower than those of the central HVAC.

Turn off lights not in use. Their heat adds a burden to your cooling system in summer and they are an expensive way to heat a room in winter.

Open draperies and window blinds during the day in cold weather to allow 
sunlight to help light and warm the rooms. At night, close draperies to conserve heat. During the summer, close draperies during the day to keep heat out.

Adjust duct registers to give the most efficient air flow within a room and to provide balanced air distribution.

Stagger start-up times for individual HVAC units to reduce demand kilowatthour usage on your system and to eliminate unnecessary cooling or heating during the hours before your facility opens.

Turn down or shut off your system at night and over holidays. A recent study by the National Bureau of Standards calculated fuel savings per day for buildings in 25 cities when the thermostats were lowered by $5^{\circ}, 7.5^{\circ}$ and $10^{\circ}$ between 10 P.M. and 6 A.M. Savings in New York City, which has a cold winter climate, were $8 \%, 10 \%$, and $12 \%$, respectively.

Before closing your facility for the night, and after exhaust systems have been shut off, you may achieve energy savings by precooling (in summer) or preheating (in winter) your facility for the next day's operation, especially if your building is well sealed and large.

Where nights are substantially cooler than days, you should experiment with flushing out your facility with cool, outside air before shutting off the ventilating system.

Use direct, cold outside air for internal cooling whenever possible.

Close HVAC duct and kitchen exhaust dampers when not in use. 


\section{Building Operation}

Develop specifications for the purchase of new equipment to ensure that it is as energy efficient as possible.

Schedule night classes in rooms that are used during the day, thus utilizing existing room heat

Minimize nighttime activities that require excessive lighting

Consolidate classes or activities wherever possible to allow shutdown of some buildings or HVAC systems

Provide facilities that are the proper size to accommodate the group that will be using them

Reduce temperatures in rooms used for physical activities (i.e., shops and gyms)

Whenever possible, schedule major electrical power-consuming operations during off-peak hours

Encourage and facilitate the formation of faculty and staff carpools

Provide safe and adequate parking areas for bicycles on campus

Design and print attractive, eye-catching signs and posters promoting energy conservation

Establish an in-service training program for the maintenance and operations staff on energy conservation and energy efficiency; use experts in the field and manufacturer's representatives as instructors in the efficient operation of equipment 


\section{Food Preparation and Storage}

Almost half the total amount of energy required by a typical food service establishment is used to prepare and store food. ${ }^{*}$ Most of this energy is consumed by cooking equipment: ovens, broilers, fryers, griddles, ranges, steam cookers, and warmers. Equipment may be operating for as long as 12 hours each day, which means high energy costs. Yet about $60 \%$ of this energy may not be used to actually cook the food; it is lost as heat from cooking equipment to the kitchen. The inefficient conversion of electricity, gas, or fuel oil to cooking heat, the inefficient transfer of heat from the source to the food, and careless equipment operation all contribute to these particularly high energy losses.

Obviously, these inefficiencies are costly. While some can be corrected only by equipment manufacturers, there are other inefficiencies you can correct. Thus, the focus of each of the following sections is on ways you can operate and maintain your cooking equipment more efficiently. The major pieces of energy-consuming equipment are discussed in five separate sections:

RANGETOPS, GRIDDLES, and BROILERS

\section{OVENS}

\section{FRYERS}

\section{STEAM COOKERS}

\section{REFRIGERATORS and FREEZERS}

Some important energy conservation principles that apply to all cooking equipment appear on the following pages. 


\section{General}

Cook in the largest volume possible. Volume cooking may not be possible for your operation. However, most food service establishments find they can cook some items more energy-efficiently by cooking them partially or completely in advance. Foods may also be cooked in volume and frozen until needed. However, the energy costs associated with cooking, freezing, thawing and reheating must be considered. ${ }^{*}$ In both cases, energy and nutrition factors will have to be balanced in order to determine the applicability of volume cooking for a restaurant facility.

Cook at the lowest temperature that still gives satisfactory results. Slow cooking retards meat shrinkage and retains more nutrients and better color in all foods. Slow cooking also means lower energy consumption because a lower cooking temperature means less energy loss from cooking equipment. Even though lower temperatures also result in longer cooking times, the savings on energy losses from cooking equipment to the surrounding air are great enough to make low-temperature cooking energy-efficient.

Reduce excess heat loss by carefully monitoring preheat times, cooking temperatures, and maintenance checks. Reducing heat losses from cooking equipment is, essentially, what this appendix is about.

Some rules to follow are:

Preheat and reheat equipment no longer than manufacturer's instructions require.

Heat only to the temperature required. Do not turn thermostats on "High" in an attempt to get equipment to heat up or food to cook faster.

Select the correct piece of equipment for each task.

Use steamers to defrost and cook food, where possible.

Keep records of breakdowns, parts' replacements, and regular maintenance checks on all equipment. Poorly functioning equipment, and worn or dirty parts use energy inefficiently.

${ }^{*}$ One publication that offers recommendations on how to cook and freeze food efficiently is Cook-Freeze Food Service in Health Care Facilities (1974, 51 pages), published by the American Hospital Association, 840 Lake Shore Drive, Chicago, Illinois. Price: $\$ 1.50$. 
Reduce "peak loading."* The rate at which you are charged for electricity is dependent on three factors: the highest, or peak-demand period during each month; how much electricity, or loading is required during the hours when the entire community's demand is at peak; and your total consumption. Peak hours are usually between 10:00 A.M. and 8:00 P.M. Peak-loading control devices can be installed so that the highest demand equipment-air conditioning compressors, for example-cannot start up or surge simultaneously. Such devices have been responsible for energy bill reductions as high as $10 \%$.

Some rules to follow in reducing peak-load demand are:

Use high-energy-demand equipment sequentially rather than simultaneously, if possible. For example, try to schedule baking in the morning and roasting in the afternoon.

Schedule energy-intensive cooking, such as baking and roasting, during nonpeak demand hours.

While baking or roasting, limit the number of other pieces of electric equipment used. 


\section{"Ways to Save Gas in a Food Service Operation"}

Break the habit of turning on all your equipment first thing every morning. Unless you plan to use a piece of equipment, leave it off until it's needed.

There's no need to preheat an open-top range. and 10 to 15 minutes is all it takes for a solid-top range.

Cook with a medium to low flame. Turn the flame down when cooking temperature is reached.

Regulate the burners on an open-top range so that the flame tips just touch the bottom of the utensil.

Crowd thinning out? Turn off gas when range or other equipment is no longer in use.

Use flat-bottom utensils on solid-top ranges. Nearly any type of pot or pan can be used on an open-top range because the flame will tailor itself to the shape of the pan.

You save gas when you group pots and pans on solid-top ranges and light only the burners needed instead of the entire range top.

Never overheat a griddle in the interest of speed. The cooking results can be disastrous, and you'll waste gas.

Usually, a medium or low flame is adequate for light frying. If your griddle has a thermostat, use it to avoid wasting gas and for best results.

During slack periods, turn the burner on your griddle down. There's no point in keeping the griddle at peak when you're not busy.

Turn the broiler flame low between broiling operations and off completely during slow periods.

Operate just part of your multiple-burner broiler, unless the work load is heavy, and conserve gas.

A longer broiling time at moderate temperatures retains the juice, flavor and tenderness of foods, and saves gas and improves quality.

Slow roasting reduces meat shrinkage and saves gas.
New infrared gas broilers not only cut your broiling time in half but they preheat so quickly ( 30 to 90 seconds) that you can turn them off between broiling operations and further conserve gas.

Plan baking and roasting so that foods requiring the same temperature can be done at the same time, and then load your oven to capacity.

Dialing a higher setting won't make your oven preheat any faster. Preheat with oven thermostat set at the desired temperature.

You waste gas by opening the doors on your oven unnecessarily to check on foods. Urge employees to depend on thermostats and timers instead.

The uniformity of temperature throughout a gas convection oven lets you load its multiple cooking racks to capacity. You get more product from less space.

Conserve gas by turning on your gas fryer no more than 20 minutes before you plan to use it.

In modern, high-speed fryers, temperatures ranging from $325^{\circ}$ to $335^{\circ}$ are ideal for practically all types of fried foods. Too high a temperature makes fat break down and wastes gas

Use your fryer instead of the range top for frying but don't turn on two fryers when one will do. Turn the thermostat down or off when fry kettle is not in use, and save gas.

Use warming tables wisely. They are not cooking appliances. Learn the recommended serving temperatures for different types of foods. You can waste gas and dry out foods by excessive heat.

Keep your equipment clean and have it checked periodically-burners, pilots, thermostats and other controls. Well maintained equipment works better, lasts longer and uses less fuel.

Upgrade your operation. Today's gas equipment offers time- and fuel-saving features that help you increase production, save on gas and cut costs. Steam cookers, steam kettles and tilting skillets/ braising pans are prime examples. 


\section{Rangetops, Griddles, and Broilers}

The focus of a kitchen's activity-and energy consumption-is typically the rangetop, griddle, and broiler. As is true for most energy-consuming equipment, getting the highest energy efficiency means selecting the right equipment for the specific task, maintaining it correctly, and attending to the small, but important, details of scheduling and operation.

These details, as well as information about the types of rangetops, broilers, and griddles on the market and the energy-efficient use of each, are discussed in this section.

Rangetops and griddles are similar in that they involve the transfer of heat from a heating element through a cooking surface to the food. The size of the cooking vessel or surface, the time needed to cook the food and the menu requirements should determine the kind of rangetop, griddle, or frytop used:

Open tops are arrangements of individually controlled burners, or hotplates, with the cooking vessel placed directly on top of a gas flame or electric heating coil. Open tops are common in home kitchens. Size and design features limit their use by food service establishments to cooking quantities of less than 20 quarts. French hotplates are suitable only for light cooking, between 9 and 20 quarts. If equipped with tubular coils, they can be used for larger volume cooking of up to 40 quarts.

Closed tops have burners or electric coils positioned beneath a solid castiron or stainless steel top. Precise temperature controls permit heating either the entire top or merely some sections, depending on the need. The solid top allows the energy-efficient grouping of large pots.

Griddles and frytops are used for quick-frying and sauteing. Frytops are used to quick-fry small-volume orders; griddles are larger and more versatile frying surfaces. Griddles are suitable for variable-volume cooking because sections may be heated individually or the entire surface heated to a single temperature. Special broiler-griddles permit two distinct cooking processes to use the same heat source. An energy-efficient alternative to griddles and frytops is the deep-fat fryer for those foods that can be cooked either way. 


\section{Operation}

When cooking with gas-fired units, adjust the flame until it is entirely blue and has a distinct center cone. A yellow-orange tip indicates that some gas is not being burned, and the flame should be turned down. Gas flames should just cover the bottom of cooking pots; they should not extend over the sides. The bottoms of flat-bottomed pots should rest flush against the heating surface. The diameter of a pot should be 1 inch greater than the diameter of the electric coil or plate.

Turn down heat as soon as food begins to boil, and maintain liquids at a simmer. Remember that water and other water-based liquids boil at $212^{\circ} \mathrm{F}$. Turning the flame higher does not cook food any faster; it only uses more energy.

Cover pots to retain heated air and decrease cooking time.

Cook at the lowest temperature that will still produce satisfactory results.

Turn off units when not in use.

\section{Rangetops}

Preheat electric units no longer than the manufacturer's instructions require. Preheating times are usually 10 to 15 minutes.

Heat only the section of the closed-top range being used.

Group pots on closed-top ranges to use as little surface area as possible, then adjust heating elements to desired levels.

\section{Griddles}

Heat only those portions of the surface required by the volume of food to be cooked.

Heat only to highest temperature required by the food being prepared. A low or medium flame is best.

Rely on a thermostatic control when possible to avoid continuously high, or excessive, heat.

Use the entire heated surface when possible.

Turn off sections of the griddle during slack periods. 


\section{Broilers}

Preheat no longer than manufacturer's instructions recommend.

Monitor preheat times with thermostats or timers.

Load heated broilers to capacity when practical to utilize the entire surface area.

Heat only as many sections as required by the cooking load.

When possible, use infrared broilers, which can be turned off when not in use and quickly reheated, rather than idling less efficient equipment.

\section{Maintenance}

Periodically check all gas units for uneven or yellow flames. For electric units, check the length of preheating times. Schedule routine inspections and contact utility representatives if the unit is not functioning properly.

To correct a gas flame that is too yellow, clean the burner with a stiff wire brush to remove charred food particles. If the flame is still too yellow, have a service representative adjust the gas-to-air mixture.

\section{Open Tops}

To clean burners and coils remove encrusted matter from cool heating elements, then soak them in a mixture of water and grease solvent. Burners should be boiled in a solution of salt, washing soda, or detergent.

\section{Closed Tops}

Lift the hood to be certain that burners are functioning properly.

To clean, rub vigorously with heavy burlap or a wire brush after the top surface has cooled. Remove any cooked food lodged under burner, lid rings, or plates.

Keep burner valve handles lubricated with a high-temperature grease designed for this purpose. Your service representative can do this during regular maintenance checks.

\section{Griddles}

Scrape excess food and fat particles from the surface with a flexible spatula, 
grill brick, or other device after each cooking load.

Clean and wipe out the grease troughs, remove any stuck-on food, and clean the surface with a soft cloth, rubbing with the grain of the metal while the surface is still warm. This should be done at least once a day, and more often if the cooking load is heavy.

Using a reliable commercial thermometer, regularly check griddle surface temperature against the reading on the control dial. If the readings do not match, the thermostat may need calibrating. Many utilities and commercial maintenance companies offer this service.

\section{Infrared Broilers}

Check ceramic burners for cracks, popping sounds, blackening or crumbling-signs of deterioration that affect the efficiency of heat transfer.

\section{All Other Broilers}

Empty grease pan and wash pan, drip shields, and grids with a mild solvent to remove any residue. Scrape grid surface as needed.

Clean burners and check air shutters to be certain that gas-to-air mixture is correct. Clogged burners will slow cooking times.

Rearrange the ceramic material in under-fired broilers once a month to assure even heat.

Have gas burners checked by an experienced service representative at least yearly.

\section{Ovens}

Ovens are essential pieces of cooking equipment for most food service operations. They are also among the most energy-consuming. For each hour of operation, a typical gas bake oven consumes 75 cubic feet of gas and an electric bake oven 20 kilowatt-hours of electricity. Of that amount, only $40 \%$ to $60 \%$ is used to cook the food. The remainder of the energy is wasted to the kitchen air, often making the kitchen hot and burdening the HVAC system as well.

Ovens have been designed to perform specific tasks. The various types on the market can be classified into four categories.

Conventional ovens are standard, or range, ovens which heat food by 
conduction and radiation. They come in a wide range of sizes, although they are generally smaller than deck ovens.

Standard deck ovens have long and deep rectangular cavities that can accommodate large quantities of food. As their name implies, they are constructed in sections, one stacked on top of another. Because each section acts as a separate oven, foods can be cooked at different temperatures at the same time. Each section can also be preheated more rapidly than can a conventional oven.

Forced convection ovens are small-cavity ovens equipped with fans that circulate heated air inside the cavity. The continuous and even circulation allows many closely spaced racks of food to be cooked at the same time--much more food than can be cooked in a standard oven of a comparable size. Other energy-efficient characteristics of convection ovens are their low cooking temperatures, as well as short cooking and preheat times.

Microwave ovens use microwaves which give up energy in the form of heat that penetrates the food. Microwave ovens use a great deal less energy and, because food cooks in a fraction of the time required by other ovens, they can be very efficient cooking, reheating, and defrosting devices. However, food size, density, and shape determine their efficiency. For example, two potatoes take longer to cook than one-actually about $80 \%$ longer. To learn how and what to cook in a microwave oven takes training, and detailed manuals have been prepared by microwave manufacturers on how to use the ovens efficiently and safely.

\section{Operation}

\section{Conventional, Standard Deck, and Convection Ovens}

Start the day's baking with foods that require the lowest oven temperature.

If using electric ovens, bake during off-peak hours.

Stagger preheat times. Use other electrical appliances sparingly while preheating.

Schedule cooking times to use ovens to capacity. Cook foods, such as rice or sauces, which are not normally cooked in ovens.

Set thermostats at the lowest temperature that will still achieve desirable results. A high temperature setting will not preheat an oven faster than a moderate one; it will only waste energy.

Load ovens to capacity to utilize as much of the heat as possible. Allow at least a 2-inch clearance in standard ovens for air to circulate around pans. Con- 
vection ovens require less circulation space.

Load the entire oven at one time and as quickly as possible to minimize heat losses. The interior temperature drops about $10^{\circ} \mathrm{F}$ every second the door is open.

Rely on a timer when cooking; avoid opening the door to check food.

Use a second oven only when cooking schedules unavoidably overlap.

\section{Maintenance}

\section{Conventional and Standard Deck Ovens}

Keep lower edge of door free of food particles so the door will close evenly and seal correctly.

Keep interior walls and heating elements clean to obtain maximum heat transfer.

Every few months, have a qualified service representative calibrate the oven thermostat with a thermocouple. If your oven is not heating properly, have it checked immediately.

In any self-cleaning or continuously cleaning oven, check for dents in the surface that may affect performance.

Once a year, have a service representative thoroughly inspect the following components of your oven: burners (to adjust gas-to-air mixture), thermostat, door closings, and insulation.

\section{Microwave Ovens}

Carefully follow instructions in the user's guide. Use only recommended utensils to avoid damaging the interior surface door seals and affecting the lifespan of the magnetron tube.

Wipe up spills and keep the interior surfaces free of food particles, which affect oven efficiency.

Clean cavity with a soft cloth or sponge and mild soap. Never use abrasives, which may scar or nick the oven surface and eventually reduce efficiency.

Regularly have your service representative check the oven for radiation leaks; they waste energy and can be dangerous.

At least once a year, have the following components professionally checked: safety interlock, magnetron, and timer. 


\section{Convection Ovens}

Follow the manufacturer's instructions for cleaning fan blades-accumulated dirt restricts the amount of air delivered.

Have the motor checked once a year.

\section{Fryers}

All commercial fryers, whether gas or electric, have two energy-saving features in common: accurate temperature controls which allow cooking times to be estimated and scheduled precisely, and fast start-up times to reduce energy losses from waste heat. New equipment heats in 10 minutes. However, fryers must be operated and maintained correctly for these controls to be effective. Below is a description of the three types of fryers currently on the market.

Deep fat (or French) fryers have deep containers, which are filled with cooking fat and heated by thermostatically controlled gas or electric heating elements to temperatures of $325^{\circ} \mathrm{F}$ to $375^{\circ} \mathrm{F}$. Electric heating elements may be either immersed in fat or located beneat the container surface. Food, in baskets, is lowered into the fat-filled container.

Pressure fryers cook foods under pressure in a manner similar to pressure steam cookers. Moisture from the food is released and transformed into steam during the cooking process. Pressure frying greatly increases the speed of cooking. Most pressure fryers are designed for foods having a high moisture content, such as chicken. However, some are equipped with moisture injection pumps which supply moisture to the system for cooking a wide variety of foods.

The tilting skillet -also called a tilting fry pan, braising pan, or griddle skillet-is an extremely versatile piece of cooking equipment which will stew, saute, simmer, boil, defrost, grill, roast, and process convenience foods. It comes in a variety of sizes, most with a heating element embedded in the base of the pan. The tilting skillet can be used efficiently for roasting at low temperatures $\left(150^{\circ} \mathrm{F}\right.$ to $200^{\circ} \mathrm{F}$ ) and for holding foods already prepared. When closed, the cover helps retain heat in the unit and enhances its energy efficiency.

\section{Operation}

Preheat according to manufacturer's instructions. Preheat times range from 7 to 15 minutes.

Turn fryer off or reduce to idling temperatures during slack periods. Use a 
second fryer only during high-volume demand.

Turn thermostat up only as high as required to reach frying temperatures $\left(325^{\circ} \mathrm{F}\right.$ to $\left.350^{\circ} \mathrm{F}\right)$. This conserves energy and improves frying time.

Do not load beyond the manufacturer's stated capacity. Usually, baskets are loaded to $1 / 2$ to $2 / 3$ capacity. Crowded food takes longer to cook, wasting energy.

Check fat level frequently; food must be covered with fat to cook correctly. Add fresh fat if level has dropped below marker.

\section{Maintenance}

Filter sediment from cooking fat as necessary. Built-up sediment reduces cooking efficiency.

Clean heating elements at least once a week, and daily if you do highvolume frying. Remove any burned food or grease that would interfere with efficient operation.

Clean grease and food particles from exhaust hoods. Clean filters regularly. (See HVAC chapter of this guide for a discussion of exhaust systems.)

Inspect and clean interiors of fixed-well fryers for grease or carbon deposits.

Check the temperature of cooking fat regularly, using a reliable commercial thermometer, to be certain that heating elements and thermostat controls are working correctly.

\section{Steam Cooking and Holding}

Steam is an effective alternative to conventional moist-heat cooking rangetops. Steam cooking is highly efficient because:

Steam always remains at temperatures of $212^{\circ} \mathrm{F}$ (atmospheric pressure) to $250^{\circ} \mathrm{F}$ (under pressure of $151 \mathrm{psi}$ ) and, therefore, is a moderate, uniform cooking medium.

Steam transfers its heat to food rapidly.

Steam equipment requires little or no warm-up time except to create the steam; 
thus, preheat and idling losses are minimal.

Cooking times are usually much shorter than for rangetop cooking or boiling.

Steam is also a highly efficient heat source. It may be generated for use by food service facilities in the following ways:

Piped in and purchased from a utility owned by a city or commercial complex.

Generated onsite-usually by a large hotel, hospital or university-and piped to the kitchen.

Created in the kitchen for all equipment by a single steam generator or by smaller individual generators attached to each steam appliance.

Descriptions of the energy efficiencies of the several kinds of steam cooking and holding equipment follow.

Pressurized and unpressurized steamers, also known as compartment, deck, or convection steamers, admit steam to a relatively large cooking chamber. As steam comes in contact with the cold food, it condenses to water. Unpressurized convection steams are less energy-efficient than other types because steam is free-vented down the drain.

Both unpressurized and pressurized steamers cook food very rapidly. However, pressurized steamers are more energy-efficient because steam is in direct contact with the food, not the metal pot. They operate at 5 to 15 pounds of pressure per square inch to raise the cooking temperature to $250^{\circ} \mathrm{F}$. The water condenses inside the steamer, then is drained off and exhausted.

Steam-jacketed kettles are energy-efficient alternatives to rangetop cooking. If well insulated, they are especially efficient.

Steam tables are large tanks, filled with about 3 inches of water, and heated with steam, gas, or electricity. Food trays are set on the table cutout, slightly above the water, at temperatures which inhibit the growth of microorganisms. There are also "steam" tables which use air as a heating medium.

Bain marles are a version of steam tables. They differ in that the food tray is set into the water bath. Unlike steam cooking equipment, warming tables are highly inefficient. A recent study conducted by the Sheraton Corporation determined that steam tables consume more energy than any other kitchen equipment. 


\section{Operation}

Fill cooking vessels according to manufacturer's recommendations, and to capacity, if possible. The amount of steam used is almost the same whether cooking a small or large amount of food.

Turn off steam unless actually cooking. Preheat times are short; therefore, equipment should not be kept running.

Thaw frozen food in steam vessels rather than in boiling water. Racks of frozen food may be thawed in volume. However, food should be spaced to allow steam to circulate around each item and, once thawed, immediately cooked through.

Where possible, begin cooking food in a steamer, then finish it with your usual cooking process.

Maintain the temperature of steam tables at a level that will keep food warm without allowing clouds of steam to form. Clouds of steam indicate unnecessarily high temperatures. Monitoring the temperature in this way on all cooking equipment reduces both the amount of energy required to operate the steam table and the load on the HVAC system.

\section{Maintenance}

Repair all steam leaks, no matter how small. Even a small leak will increase the load on your HVAC system.

Keep equipment lids and door seals clean and free of debris to prevent steam leakage to the kitchen.

Inspect the insulation on steam lines for damage.

Light-gauge sheet metal may be used to protect insulation where steam lines are exposed to damage. If damaged, replace insulation.

Check the steam traps on all steam equipment.

Flush boilers at least weekly, following manufacturer's instructions. Flushing removes water-formed substances originally in the water which become deposited in the boiler and which seriously reduce the efficiency of the boiler. Occasionally, and especially where local water is hard, boilers should be cleaned with a commercial chemical cleaner sold for this purpose.

Clean steam cooking equipment periodically to remove lime deposits. Lime acts to insulate the equipment and reduce its effectiveness. It is important to follow the manufacturer's directions and establish a schedule for cleaning. In localities where lime deposits are heavy, install a water conditioner to reduce deposits in steam equipment. Whenever cleaning steam cooking equipment, remember to use a nontoxic cleaner. 


\section{Refrigerators and Freezers}

Every food service facility stores perishable food in refrigerators and freezers. When opeating properly, these appliances account for roughly $2 \%$ of a typical food service operation's energy budget. ${ }^{*}$ However, if inefficiently used and poorly maintained, energy consumption can become unnecessarily high.

All refrigerators and freezers consist of a mechanism to remove the heat, a container to prevent the infiltration of heat, and various openings for access to the food stored within. Energy is consumed only to remove the heat, but the quantity of energy used is heavily dependent on the size of the interior and number of doors. The cooling unit consists of a compressor, evaporator, condenser, and expansion valve, just as are found in an HVAC chiller system. The evaporator is located inside the unit, whereas the other components may be located either inside the refrigerator/freezer, as is common for small units, or at a remote location. The quantity of heat given off from a large unit makes it desirable to locate the compressor and condenser mechanisms outdoors.

Refrigerator and freezer walls contain insulation of glass fiber or plastic foam. Doors and latches are equipped with gaskets to prevent cold air losses at these points.

In the following sections, recommendations are made that will ensure the efficient operation of your refrigerators and freezers. 


\section{Operation}

Refrigerators and freezers are so simple to operate that little thought is usually given to operating them in an energy-efficient manner.

Open doors as seldom as posible. Try to plan ahead, and take out or replace several items at one time, so that frequent openings are not necessary.

Clearly label stored items. Place those frequently used near the front of the unit to reduce the time the doors are open.

Be sure that items are not jammed against doors when closed. They can damage the door gaskets and cause leaks.

Allow hot food to cool briefly, in accordance with safe food handling practices, before refrigerating or freezing.

\section{Maintenance}

Condenser. Clean fins and plates regularly. Frequently remove grease from condensers located in or near the kitchen; grease builds up rapidly and impairs the cooling capability.

Leveling. Refrigerators and freezers should be leveled so that the doors fit correctly and close automatically from an open position.

Hinges and latches. Lubricate hinges and latches monthly with good grade oil. Cooking or mineral oil can be used for this purpose.

Temperature. Keep thermometers properly calibrated to ensure that desired temperature is maintained. Keep thermometers inside units at eye level.

Insulation. Periodically (more frequently for a new unit), feel the outside walls for cold spots. A cold spot indicates that the insulation has shifted or is waterlogged. Contact the manufacturer if you spot this problem.

Defroster. If the unit has an automatic defrost cycle, ask a trained refrigeration service technician to adjust it and be certain that it is used only when necessary. Set the defrost cycle so the freezer will defrost after usual operating hours. If the unit does not have an automatic defroster, defrost as necessary. Be sure the evaporator is kept free of frost.

Door gaskets. Check gaskets for cracks or other damage and remove accumulated debris. A piece of paper inserted between the gasket and door frame should resist withdrawal when the door is closed. Make this test around all sides of the door, even the hinge side. 


\section{Service Hot Water}

\section{Dishwashers}

Most restaurants reuse tableware and, therefore, require dishwashing machines to clean and sanitize dishes and utensils rapidly. Although the range of dishwashers available is impressive, dishwashing techniques are fairly standard. Wash water is maintained at a constant temperature, usually by an electric heater, and may be reused. Rinse water may also be partially recycled in a two-tank unit. The final rinse uses clean, once-through water at temperatures ranging from $165^{\circ} \mathrm{F}$ to $190^{\circ} \mathrm{F}$ which are specified by city and state health regulations.

When used properly, dishwashers are efficient and operate at a relatively low energy cost. The following sections suggest steps that you can take in operating, maintaining, and planning to ensure that your dishwasher system uses as little energy as possible.

\section{Operation}

Fill your dishwasher to capacity. The same amount of energy is used whether or not the racks are full, so schedule your dishwashing prudently. Be sure that the operator knows how to load racks fully and space tableware closely together on a conveyor system.

If a power dryer is used, adjust it so that heated air is delivered just long enough to barely dry the dishes. Remember that drying will continue after the machine is shut off. Consult your maintenance manual for instructions on how to make the adjustment and then experiment to find the right setting.

Consider using a wetting agent in the dishwasher, which will eliminate the need for power drying.

\section{Maintenance}

The best source of maintenance information is the owner's manual that comes with your dishwasher. Here are a few maintenance suggestions that pertain specifically to energy conservation:

Clean lime deposits from spray nozzles and tanks; these deposits reduce the effectiveness of the unit. Nozzles should be reamed with a wire when white deposits become visible at the openings.

Check the temperature of the rinse water. Exceeding the required 
temperature wastes hot water, accelerates lime build-up, and puts an extra load on the HVAC system.

Inspect the feed and drain valves weekly for water leakage which, in time, can waste a large quantity of hot water.

Inspect pumps monthly for water leakage.

Regularly check the speed reducer on conveyor-type washers for proper lubrication. Either too much or too little lubrication will result in additional energy consumption and may cause the motor to burn out prematurely. Your maintenance manual will tell you where and how to check the lubrication level.

\section{Modifications}

Provide an exhaust hood close to the dishwasher to carry wet air out of the kitchen before it burdens the HVAC system. Try to have this blower activated automatically by the dishwasher cycle mechanism so that it operates only when required.

Investigate the possibility of installing a low-temperature dishwashing system that uses a sanitizing solution and $110^{\circ} \mathrm{F}$ water. Before installing any lowtemperature system, check with local authorities to be certain that it meets health regulations.

Be sure that the pressure of the dishwasher supply water is within the manufacturer's recommended limits. Dishes will not be throughly rinsed if the pressure is low, and high water pressure wastes heated water.

Install thermometers in the wash tap and in the hot rinse water line that feeds the dishwasher so that the performance of the heating units can be checked. The temperature reading should be consistent with local health codes.

Investigate the possibility of different heat recovery methods. For example, waste-heat ovens, etc., can sometimes be used to preheat water supplied to hot water heaters.

\section{WATER HEATERS}

Water heating systems heat water to temperatures appropriate for dishwashing, food preparation, and lavatories. A water heater provides hot water to faucets in one of two ways: water can be heated to the temperature at which it will be used at the faucet, or it can be heated to a higher temperature, stored, and tempered with cold water before it reaches the faucet. Some food service estab- 
lishments maintain separate water heating systems for kitchen and lavatory use. One system generates very hot water to be piped to the kitchen where it is needed; the other warms water for the lavatories where moderate temperatures are adequate.

All forms of energy can be used to heat water. Most food service establishments use electric or gas water heaters, although a few use oil or steam. Electric water heaters are efficient at converting electrical energy to hot water. However, they generally heat water more slowly than do other kinds of heaters and require a larger tank to keep an adequate supply of water available.

You can reduce your energy usage for water heating by understanding how energy losses occur and how to operate and maintain the system efficiently.

\section{Operation}

You can obtain significant energy and dollar savings by keeping two basic objectives in mind. First, reduce the amount of hot water you use. Every time water is used, some is wasted. The lower the temperature of the wasted water, the lower the energy loss. Second, reduce the temperature of the water to the lowest temperature appropriate for the use. Why? Because heat losses from distribution pipes are related directly to the difference between the temperature of the water in the pipes and that of the surrounding air. When the water temperature is reduced from $180^{\circ} \mathrm{F}$ to $125^{\circ} \mathrm{F}$, heat loss from the pipes is halved in a $70^{\circ} \mathrm{F}$ room. The procedures described below are based on these principles.

Use hot tap water for cooking, whenever possible, except in localities where water contains concentrations of heavy metals. Although cold water is desirable for some kinds of cooking, a water heater uses less energy than a rangetop to heat the same amount of water.

Heat water only to the temperature needed. Only the rinse water for the dishwasher needs to be heated to $180^{\circ} \mathrm{F}$. Most dishwashing boosters require entering water to be $140^{\circ} \mathrm{F}$ in order to provide $180^{\circ} \mathrm{F}$ water to the dishwasher for rinsing. Water for rest rooms should be heated only to a temperature comfortable for hand washing (approximately $110^{\circ} \mathrm{F}$ ). Hot water should not have to be mixed with cold to achieve a comfortable temperature. Ask your service representative to adjust the automatic tempering valve on your water heater or to install a valve if there isn't one.

Water heaters should be located as close as possible to the demand source. Cutting the length of hot water piping by $50 \%$ reduces the potential heat 
loss by $50 \%$. Hot water boosters should be located within 5 feet of a dishwasher to avoid heat loss in the pipes.

Install spring-operated valves on your kitchen and rest room faucets to save water. One type is attached to hand levers and another operates with a foot treadle. For kitchen sinks, spring-operated foot treadles are most effective because they leave the operator's hands free for other tasks. For lavatory faucets, a 15second delay-action valve is required to satisfy health standards.

\section{Maintenance}

Whatever your water-heating system, some energy losses are inevitable.

\section{Fuel-fired heaters waste energy:}

When fuel is not burned and escapes up the stack

When an excessive amount of heat is exhausted up the stack

From the walls of the distribution pipes as hot water in the pipe cools

Steam water heaters waste energy unless the steam is condensed as it passes through the heater. Of course, losses along distribution lines can occur as well. Although it is impossible to eliminate losses entirely, you can reduce them by knowing how to check your water heater for excessive losses. The table below lists the symptoms of an energy loss and tells you what adjustments probably need to be made to correct it. If you spot a problem call your service representative.

Good preventive maintenance, however, will help to avoid many problems. Here are three simple preventive maintenance procedures that will ensure the efficient performance of the water heating system:

Drain and flush the water heater every 6 months. With normal use, water heaters accumulate solids that act as insulation and prevent the efficient transfer of heat to the water. These deposits can be removed by periodically flushing water and sediment from the unit. To do so, open the drain valve and drain 2 to 5 gallons of water from the tank until it flows clear. In those parts of the country where the water contains heavy amounts of lime or other sediment, you are advised to drain your heater monthly.

Check the insulation on hot water pipes and replace or repair it as needed.

Check the steam trap (See information on the following two pages.) 


\section{How a Steam Trap Works}

Steam, at temperatures of $212^{\circ}-250^{\circ} \mathrm{F}$, is passed through tubes surrounded by the water to be heated. As the surrounding water draws heat from the steam, the steam cools and changes back to water, which is called "condensate." The condensate then flows out of the heater, through the steam trap and back into the boiler, where it is reheated and converted to steam once again. The steam trap is a device that permits condensate-but not steam-to pass out of the heater by forcing steam to condense into water before it leaves the heater.

Even though steam traps have been in existence for a long time, no one has been able to make one that is absolutely reliable. A steam trap may fail in a couple of ways: if it jams shut, neither steam nor condensate can pass through; and if it jams open, steam blows through the trap, wasting energy and causing problems in other parts of the system.

The location of the steam trap varies with each type of water heater. If you don't know where the steam trap is, ask your service representative. Checking a steam trap is easiest if there is a test valve, but many steam heaters are not fitted with these. Even if there is no test valve, you can make a rough test of the trap. 


\section{Checking the Steam Trap}

The recommended method for testing a steam trap involves using a test valve. If the system does not include one, you should consider having one installed.

\section{If there is no test valve:}

1. Put on canvas-type work gloves

2. Simultaneously grasp the pipes entering and leaving the trap to determine whether there is a marked difference in temperature

If the temperature difference is obvious, the trap is working normally. If the temperature change is not obvious, the trap is probably stuck open, wasting steam.

Defective steam traps can also be located with an ultrasonic detector, a surface temperature gauge, a stethoscope, temperature-indicating crayons, or a color-changing, heat-activated tape. The tapes and crayons shift color when a trap passes "hot" steam instead of "cold" condensate.

If the trap is faulty, contact your steam service company. 


\section{Determining Energy Losses in Water Heaters}

\begin{tabular}{|l|l|l|l|}
\hline $\begin{array}{l}\text { Type of } \\
\text { Water Heater }\end{array}$ & What to Check For & Source of Loss & $\begin{array}{l}\text { Sol just } \\
\text { to be }\end{array}$ \\
\hline Electric, Gas, Oil or Steam & Feel for local hot spots & $\begin{array}{l}\text { Heat loss through surface } \\
\text { of unit }\end{array}$ & Have insulation checked \\
\hline Gas or Oil & Smoky exhaust & Unburned fuel escaping & Have burner adjusted \\
\hline Electric, Gas, Oil or Sieam & $\begin{array}{l}\text { Hot stack and high CO, } \\
\text { level in the exhaust }\end{array}$ & $\begin{array}{l}\text { Excessive heat flow in } \\
\text { the exhaust } \\
\text { insulation on pipes }\end{array}$ & $\begin{array}{l}\text { Have stack temperature and } \\
\text { CO. } \\
\text { adjusted, and heater } \\
\text { cleaned or flushed }\end{array}$ \\
\hline Steam & $\begin{array}{l}\text { Steam flow through trap } \\
\text { distribution pipes }\end{array}$ & $\begin{array}{l}\text { Defective steam trap } \\
\text { Add insulation io the hot }\end{array}$ \\
\hline
\end{tabular}




\section{Economics}

\section{Economic Evaluation of Energy Conservation Projects}

The business manager probably has had ample experience in performing economic evaluations. However, energy conservation projects require that all costs (including acquisition, maintenance and repair, and operating expenses) and savings which occur over the useful economic life of the project be considered.

Ranking interdependent projects is a problem which results from the fact that the savings from one conservation project may be significantly affected by the implementation of another. One approach to this problem is to evaluate each project independently, select the one that seems the best, and adjust the conditions of other projects to assume the implementation of the first. It is also important to note that the cost effectiveness of a capital expenditure to make an adjustment to an existing system will be adversely affected by the possibility that the entire system may be replaced in a few years to convert to a more efficient one.

The details of a life-cycle cost analysis are beyond the scope of this handbook. A glossary of selected economic terms has been included to facilitate your understanding of the concepts involved. The engineering economics text cited in the bibliography contains detailed descriptions of life-cycle costing methods. 


\section{Glossary of Economic Terms}

$B A S E$ YEAR. The year to which all past and future costs are converted.

CONSTANT DOLLARS. Values expressed in terms of the general purchasing power of the dollar in the base year. Constant dollars do not reflect price inflation.

COST EFFECTIVE. Estimated benefits or savings from an energy conservation project are equal to or exceed the costs of the investment where both are assessed over the life of the project.

CURRENT DOLLARS. Values expressed in terms of actual prices of each year. Current dollars reflect inflation.

DIFFERENT ENERGY ESCALATION RATE. The expected difference between the rate of cost increases assumed for energy and the general rate of inflation.

DISCOUNT RATE. The rate of interest reflecting the time value of money that is used to convert benefits and costs occurring at different times to a common time (so that they may be compared).

DISCOUNT FACTOR. A multiplicative number for converting costs and benefits occurring at different times to a common basis. Discount factors are obtained by solving a discount formula based on one dollar of costs or benefits and the assumed discount rate. Discount formulas and factors for various economic situations can be found in engineering economics texts such as the one cited in the bibliography.

DISCOUNTED PAY-BACK PERIOD. The time required for the annual net benefits derived from an investment to pay back the investment, considering the time value of money. Does not consider savings accrued after the breakeven point.

ECONOMIC LIFE. The period over which an investment is considered to be the lowest cost alternative for satisfying a particular requirement.

INFLATION. An increase in the volume of money and credit relative to available goods resulting in a substantial and continuing rise in the general price level.

INVESTMENT OR INITIAL COST. The total cost, including planning, design, and construction, necessary to provide a finished project ready for use.

MAINTENANCE AND REPAIR COST. The total of labor, material, transportation, and other related costs incurred in conducting corrective and preventive maintenance and repair on a building and its systems and equipment.

OPERATING COST. The expenses incurred during the normal operation of a building, including costs of manpower, fuel, water, etc. 
$P A Y$-BACK PERIOD. The length of time required for the stream of net cash proceeds or cash savings produced by an investment to equal the original cash outlay required by the investment; see "Discounted Pay-back Period."

$P E R I O D$. The length of time over which an investment is analyzed.

PRESENT VALUE (PRESENT WORTH). The expression of costs and savings incurred at different times as if they were all to be incurred now.

PRESENT VALUE FACTOR. The number by which a future value may be multiplied to find its value in today's dollars, based on a given discount rate.

RECURRING COSTS. Those costs which recur on a periodic basis throughout the life of a project (e.g., energy costs).

RESIDUAL (SALVAGE) VALUE. The net sum to be realized from disposal of an asset at the end of its economic life or at the end of the study period.

SENSITIVITY ANALYSIS. Testing the outcome of an evaluation by altering one or more system parameters from the initially assumed values.

SINGLE PRESENT-VALUE FACTOR. A multiplicative number to be used to find the present value of a future nonrecurring cost (e.g., repair).

SUNK COST. A cost incurred prior to an analysis and one, therefore, that should not be considered in measuring the economic performance of an investment alternative.

TIME VALUE OF MONEY. The difference between the value of a dollar today and its value at some future time if invested today at a stated rate of interest. (Also called the "opportunity cost of money.")

UNIFORM PRESENT VALUE FACTOR. The appropriate multiplier to be used to find the present value of a future cost of savings which recurs uniformly every year of the study period (e.g., energy costs). 


\section{Conversion Factors}

\section{Some Energy Units \& Conversion}

\section{Units of Energy}

1 kilocalorie (kcal) warms 1 kilogram $(2.2 \mathrm{lb})$ of water $1^{\circ} \mathrm{C}\left(1.8^{\circ} \mathrm{F}\right)$

1 British thermal unit (Btu) warms $1 \mathrm{lb}$ of water $1^{\circ} \mathrm{F}$

1 foot-pound (ft-lb) lifts 1 pound 1 foot

1 joule $(J)$ lifts 1 kilogram 10.2 centimeters (4 in)

\section{Units of Power}

1 watt $(W)=1$ joule/second

1 kilowatt $(\mathrm{kW})=1000$ watts
1 megawatt $(\mathrm{MW})=1000 \mathrm{~kW}$

1 horsepower $(\mathrm{hp})=33,000 \mathrm{ft}$. $\mathrm{lb} /$ minute

\section{Conversion Factors}

1 kilowatt-hour $(\mathrm{kWh})=860 \mathrm{kcal}=3413 \mathrm{Btu}=3,6000,000 \mathrm{~J}$

$1 \mathrm{kcal}=4184 \mathrm{~J}=3.97 \mathrm{Btu}=3080 \mathrm{ft}-\mathrm{lb}$ ( $\mathrm{a}$ food calorie is a kcal)

$1 \mathrm{Q}($ Quad $)=10^{15} \mathrm{Btu}$

$1 \mathrm{hp}=746$ watts; $1 \mathrm{~kW}=1.34 \mathrm{hp}$

$2500 \mathrm{kcal} /$ day $=121$ watts $=1$ average American food diet

12,000 watts $=1$ average American nonfood energy diet

\section{Energy Content of Fuels}

$1 \mathrm{lb}$ TNT $=478 \mathrm{kcal}$

$1 \mathrm{lb}$ bread $=1300 \mathrm{kcal}=5150 \mathrm{Btu}$

$1 \mathrm{lb}$ wood $=1800 \mathrm{kcal}=7150 \mathrm{Btu}$

$1 \mathrm{lb}$ Eastern coal $=3300 \mathrm{kcal}=13,100 \mathrm{Btu}$

$1 \mathrm{lb}$ crude oil $(0.14 \mathrm{gal})=4800 \mathrm{kcal}$

1 barrel $(\mathrm{bbl})=42 \mathrm{gal}$

$1 \mathrm{lb}$ gasoline $(0.18 \mathrm{gal})=5700 \mathrm{kcal}=22,000 \mathrm{Btu}$
$1 \mathrm{lb}$ natural gas $\left(25 \mathrm{ft}^{3}\right)=6600 \mathrm{kcal}$

1 therm $=100,000 \mathrm{Btu}=25,200 \mathrm{kcal}$

$1 \mathrm{lb}$ uranium $235=8.6$ billion $\mathrm{kcal}$ (note: in nature you find $140 \mathrm{Ib} \mathrm{U}^{238}$ to $1 \mathrm{lb} \mathrm{U}^{235}$ )

1 ton Eastern coal $=26$ million Btu

1 barrel crude oil (42 gallons) $=5.8$ million $\mathrm{Btu}$ 1000 cubic feet natural gas $=1,000,000 \mathrm{Btu}$

There are about seven barrels of crude oil to a ton. Often all energy is expressed in metric ton coal equivalents (about 28 million Btu) or barrels of oil equivalent (BOE). 


\section{Abbreviations Used}

Term
kilowatt
megawatt
gigawatt
kilowatt-hour
million BPD
million TPY
billion CFD
trillion CFY

Abbreviation

$k W e$

mWe

GWe

kWh

MBPD

MTPY

BCFD

TCFY

The following conversion factors can be used to obtain the oil equivalent expressed in million barrels per day (MBPD).

\begin{tabular}{c|cl} 
To Obtain & Divide & By \\
Btu per year & $2.12 \times 10^{15}$ \\
mQ's & 2.12 \\
MBPD & MTPY of Eastern coal & 86.8 \\
MTPY of Western coal & 125 \\
BCFD of natural gas & 5.63 \\
TCFY of natural gas & 2.06 \\
Thil Equivalent & 10 joules per year & 2.23
\end{tabular}




\section{Energy Unit Conversion Chart*}

\begin{tabular}{|c|c|c|c|c|}
\hline Natural gas, ${ }_{f^{3}}{ }^{\star \star}$ & $\begin{array}{l}\text { Oil, } \\
\text { bbil }\end{array}$ & $\begin{array}{l}\text { Bituminous, } \\
\text { short tons }\end{array}$ & $\begin{array}{c}\text { British thermal } \\
\text { units }\end{array}$ & $\begin{array}{c}\text { Electricity, } \\
\text { kWhr }\end{array}$ \\
\hline $\begin{array}{c}- \\
1 \\
3.41 \\
1000(1 \mathrm{MCF}) \\
3413 \\
5600 \\
25,000 \\
1 \text { million (1 MMCF) } \\
3.41 \text { million } \\
1 \text { billion (1 BCF) } \\
1 \text { trillion (1 TCF) }\end{array}$ & $\begin{array}{c}-\overline{00018} \\
0.00061 \\
0.18 \\
0.61 \\
1 \\
4.46 \\
180 \\
610 \\
180,000 \\
180 \text { million }\end{array}$ & $\begin{array}{c}-\overline{0} \\
0.00004 \\
0.00014 \\
0.04 \\
0.14 \\
0.22 \\
1 \\
40 \\
140 \\
40,000 \\
40 \text { million }\end{array}$ & $\begin{array}{c}1 \\
1000 \\
3413 \\
1 \text { million } \\
3.41 \text { million } \\
5.6 \text { million } \\
25 \text { million } \\
1 \text { billion } \\
3.41 \text { billion } \\
1 \text { trillion } \\
1 \text { quadrillion } \\
\text { (quad) ( } Q \text { ) }\end{array}$ & $\begin{array}{c}0.000293 \\
0.293 \\
1 \\
293 \\
1000 \text { (1 MWhr) } \\
1640 \\
7325 \\
293,000 \\
1 \text { million (1 GWhr) } \\
293 \text { million } \\
293 \text { billion }\end{array}$ \\
\hline
\end{tabular}




\section{General Glossary}

Btu (British thermal unit). The amount of energy required to heat 1 pound of water 1 degree Fahrenheit at standard physical conditions.

COMPRESSOR. A machine for reducing the volume of a given refrigerant vapor.

CONDENSER. A vessel or arrangement of pipes or tubing in which a vapor (gas) is liquefied (changes state) by removal of heat.

CONDUCTION. Transfer of heat through matter by communication of kinetic energy from particle to particle.

CONDUCTIVITY. The measure of the capability of conducting heat.

CONVECTION. The transfer of heat by the movement of fluid (liquid or gas).

DAMPER. A valve or movable plate in a duct or flue for regulating the flow of air or other gas.

DEGREE-DAYS (COOLING). The difference between the median temperature of any day and $65^{\circ} \mathrm{F}$ when the median temperature is greater than $65^{\circ} \mathrm{F}$. (For example: if the median temperature for a specific day is $78^{\circ} \mathrm{F} ., 13$ cooling degree days would be accrued).

DEGREE DAYS (HEATING). The difference between the median temperature of any day and $65^{\circ} \mathrm{F}$ when the median temperature is below $65^{\circ} \mathrm{F}$.

DELTA-t (TEMPERATURE DIFFERENTIAL). Difference in temperature between two substances or surfaces. Controls the rate of heat transfer.

DRY-BULB TEMPERATURE. The temperature of a substance as indicated by an ordinary thermometer. Indicates the sensible heat content.

ENERGY. The capacity for doing work.

ENTHALPY. A thermodynamic quality that is the sum of the internal energy of a body and the product of its volume multiplied by the pressure. The total heat content above a fixed data point (in Btu/lb), including sensible and latent heat. 
EQUIVALENT SPHERE ILLUMINATION. Illumination falling on a task, or on an area, covered by an imaginary transparent sphere which passes light of the same intensity through each unit area.

FOOT-CANDLE. A unit of illuminance on a surface that is everywhere 1 foot from a uniform point source of 1 candle and equal to 1 lumen per square foot.

HEAT CAPACITY. The quantity of heat required to raise the temperature of 1 cubic foot of a material 1 degree Fahrenheit.

HVAC. Heating, ventilation, and air-conditioning systems.

INFILTRATION. Movement of air from outside into the heated space of a building through cracks around doors, windows, walls, roofs, and floors.

INSOLATION. Total amount of solar radiation incident upon a surface exposed to the sky (in Btu/hr/ft ${ }^{2}$ ).

INSULATION (THERMAL). A material having a relatively high resistance to heat flow, and used principally to retard heat flow.

LANGLEY. A unit of measurement of radiation (esp. solar). One langley equals 1 gram-calorie per square centimeter, or $3.69 \mathrm{Btu} /$ per square foot.

LATENT HEAT. Thermal energy absorbed or evolved in a process (such as fusion or vaporization) other than temperature change.

LUMEN. A unit of luminous flux equal to the light emitted in a unit solid angle by a uniform point source of 1 candle.

LUMEN EFFICIENCY. The ratio of the total luminous flux radiated by any source to the total radiant flux from that source (in lumens per watt).

LUMINAIRE. A complete lighting unit including lamp, shade, reflector, fixture, and other accessories.

POWER. The time rate at which work is done.

POWER FACTOR. The ratio of the mean actual power in an alternating current circuit (in watts) to the apparent power (in volt-amperes). 
R-VALUE (THERMAL RESISTANCE). Measure of the tendency of a material to retard heat flow.

RADIANT ENERGY. Energy traveling as a wave motion, specifically the energy of electromagnetic waves.

RADIATION. The process of emitting radiant energy in the form of waves or particles.

REFRIGERANT. Working fluid in a refrigeration cycle, which absorbs heat from a reservoir at a low temperature and rejects heat at a higher temperature.

RELATIVE HUMIDITY. A measure of the degree of saturation of the air at any drybulb temperature.

RETROFIT. Modifications made to update existing equipment or structures.

SENSIBLE HEAT. Thermal energy the transfer of which to or from a substance results in a change in temperature.

SHADING COEFFICIENT. Ratio of solar radiation passing through a specific glazing system to the solar radiation passing through a single layer of double strength glass.

SPECIFIC HEAT. The amount of heat (Btu) required to raise the temperature of 1 pound of a material 1 degree Fahrenheit. The specific heat of water is 1.

THERM. 100,000 Btu.

TONS OF REFRIGERATION. One ton of refrigeration equals $12,000 \mathrm{Btu} / \mathrm{hr}$.

U-VALUE (COEFFICIENT OF HEAT TRANSFER). Rate of heat loss through a building surface.

WATT. A unit of power equal to one absolute joule per second.

WET-BULB TEMPERATURE. The temperature indicated by a wet-bulb thermometer (one with a moistened bulb). 


\section{Interested Associations}

Most of the following organizations have local chapters that can provide information about energy management as it applies to your climatological region.

American Council on Education

One Dupont Circle

Washington, D.C. 20036

National Association of College and University Business Officers

One Dupont Circle

Washington, D.C. 20036

Association of Physical Plant Administrators of Universities and Colleges (APPA)

11 Dupont Circle

Suite 250

Washington, D.C. 20036

Air Conditioning and Refrigeration Institute (ARI)

1815 N. Ft. Meyer Drive

Arlington, Virginia 22209

American Boiler Manufacturers Association (ABMA)

1500 Wilson Boulevard,

Suite 317, AM Building

Arlington, Virginia 22209

American Gas Association (AGA)

1515 Wilson Boulevard

Arlington, Virginia 22209

American Institute of Architects (AIA)

1735 New York Avenue, N.W.

Washington, D.C. 20006

American Institute of Plant Engineers (AIPE)

1021 Delta Avenue

Cincinnati, Ohio 45208

American National Standards Institute (ANSI)

1430 Broadway

New York, N.Y. 10018 
M Continued

American Society of Heating, Refrigeration and Airconditioning Engineers (ASHRAE)

345 E. 47th Street

New York, N.Y. 10017

American Society of Mechanical Engineers (ASME)

345 E. 47th Street

New York, N.Y. 10017

American Society of Plumbing Engineers (ASPE)

15233 Ventura Boulevard

Suite 616

Sherman Oaks, California 91403

American Society for Testing and Materials (ASTM)

1916 Race Street

Philadelphia, Pennsylvania 19103

Edison Electric Institute

90 Park Avenue

New York, N.Y. 10016

Illuminating Engineering Society of North America (IES)

345 E. 47th Street

New York, N.Y. 10017

Institute of Electrical and Electronics Engineers (IEEE)

345 E. 47th Street

New York, N.Y. 10017

National Electrical Contractors Association

7315 Wisconsin Avenue

Washington, D.C. 20014

National Electrical Manufacturers Association

2101 L Street, N.W.

Washington, D.C. 20037 


\section{Bibliography}

1. F.S. Dubin, H.L. Mindell, and S. Bloome, "How to Save Energy and Cut Cost in Existing Industrial and Commercial Buildings, in An Energy Conservation Manual, Noyes Data Corporation, Park Ridge N.J. 1976. (This manual is invaluable. It describes low cost conservation measures, engineering changes, team approaches, computer programs, economics and cost benefit analyses along with pragmatic data for quick calculations and descriptions of all major systems and components to be found in any building.)

2. Total Energy Management, U.S. Department of Commerce, National Electrical Manufacturers Association and the National Electrical Contractors Association, U.S. Government Printing Office, March 1976. (A practical handbook on energy conservation and management. This booklet describes the team approach in great detail as well as the more commonly used conservation options.)

3. "Energy Conservation on Campus," Vol. 1, Guidelines, Federal Energy Administration, FEA/D-76/229, 1976. (A useful simple set of guidelines is outlined in this publication.)

4. "Energy Cost and Consumption Audit Program," a report of the Energy Task Force, published by the Association of Physical Plant Administrators, 1977. (This is a continuing assessment of the efficacy of energy conservation throughout the United States. Comparison data could be useful for your own institutional needs.)

5. "Establishing Energy Conservation Standards for New residential Buildings and Non-Residential Buildings," State of California Regulations, California Energy Resources Conservation and Development Commission, Conservation Division (effective from July 1st 1978). (These performance standards for new buildings, including schools and colleges, describe what will be required insofar as energy use is concerned.)

6. "School Lighting," Lighting Design and Application, Feb. 1978. Most of this issue is devoted to the topic of adequate and efficient school lighting.

7. "California School Lighting Design and Evaluation," California State Department of Education, 1977. (This paper describes procedures that can be followed to enable the quality and efficacy of school lighting to be calculated in existing systems.) 
8. Grant, Eugene L. and Treson, W. Grant, Principles of Engineering Economy, 5th edition, Ronald Press, New York, 1970.

9. Energy Management for Colleges and Universities, Association of Physical Plant Administrators, One Dupont Circle, Suite 510, Washington, D.C. 20036, 1977.

10. American Society of Heating, Refrigeration and Air conditioning Engineers Handbook of Fundamentals, ASHRAE, 345 E. 47th St., New York, 1972.

11. IES Lighting Handbook, Fifth Edition, Illuminating Engineering Society, 345 E. 47th St., New York, 1972. 
This report was done with support from the Department of Energy. Any conclusions or opinions expressed in this report represent solely those of the author(s) and not necessarily those of The Regents of the University of California, the Lawrence Berkeley Laboratory or the Department of Energy.

The discussion of certain named companies or brand name products is not intended as a recommendation of them over other companies or similar products in the market, nor is their selection for discussion intended as an endorsement or warranty. 